\title{
I. DEFINITIONS AND LABORATORY TECHNIQUES OF COMPRESSIONAL SOUND VELOCITY PARAMETERS AND WET-WATER CONTENT, WET-BULK DENSITY, AND POROSITY PARAMETERS BY GRAVIMETRIC AND GAMMA RAY ATTENUATION TECHNIQUES
}

\author{
Robert E. Boyce, Scripps Institution of Oceanography, La Jolla, California
}

\section{INTRODUCTION}

On Leg 33 of the Deep Sea Drilling Project the following physical properties were all measured on the same "undisturbed" samples: sound velocity, wet-bulk density (ratio of the weight of wet-saturated sediment to its volume, $\mathrm{g} / \mathrm{cc}$ ), and wet-water content (ratio of the weight of sea water in the sediment to the weight of the wet-saturated sediment, expressed as percent). These parameters allowed calculation of seismic impedance, seismic reflection coefficients, and porosity (ratio of the volume of water in the sediment to the volume of the wet-saturated sediment, expressed as percent). Where possible, velocities were measured parallel and perpendicular to bedding planes, which allowed the acoustic anisotropy to be calculated.

In addition to the above individual sampling, the wetbulk density was also determined continuously using the Gamma Ray Attenuation Porosity Evaluator (GRAPE) (Evans, 1965). From this wet-bulk density analog data, porosity can be estimated using the nomogram in the core plots by using assumed or estimated grain density values.

The GRAPE device can also be run in a static 2minute counting mode for individual samples (GRAPE Special 2-Minute Count) in addition to the continuous 2 -second counting mode. Techniques for sound velocity, wet-water content, and the GRAPE device are discussed in this paper, followed by a discussion of the Leg 33 physical properties presentation.

\section{SOUND VELOCITY PARAMETERS AND TECHNIQUES}

Compressional sound velocity, at $400 \mathrm{kHz}$, through sediment, sedimentary rock, and basalt were measured with a Hamilton Frame Velocimeter, which is accurate to $\pm 2 \%$. The basic equipment and technique are described in Boyce (1973) and therefore will not be described here, except for calibration procedures with corresponding data, and sampling techniques. Various velocity parameters will also be discussed.

Sound velocity samples were not taken until the cores reached the approximate room temperature, by waiting four or more hours. After the sedimentary cores reached room temperature, they were split longitudinally, and an "undisturbed" sample was selected. For a soft sample, the criterion for nondisturbance was visibly undistorted bedding. Hard samples selected were cut perpendicular to the core with a circular diamond saw into 2.5 to 5.0 $\mathrm{cm}$ long samples with parallel ends. The saw marks on the sedimentary rock samples were removed with a sharp knife or spatula. The sample was then squirted with distilled water to be certain the cut surfaces were saturated with water. Acoustic velocity was then measured both (if possible) parallel and perpendicular to bedding planes and the room temperature was recorded. Then it was sampled for wet-water content measurement followed by a Special GRAPE 2-Minute Count for wet-bulk density, which was taken within a few minutes after the velocity measurement.

Basalt cores were left in the round with the velocity being measured across the diameter after the rough edges had been removed with a file and squirted with distilled water. ${ }^{1}$ GRAPE Special 2-Minute wet-bulk densities were measured, but water content samples were not allowed. Occasionally, velocities were measured on minicores about $2.2 \mathrm{~cm}$ in diameter, which were collected by the igneous petrologist.

Porosities of the sedimentary rock velocity samples were calculated by multiplying the salt-corrected wetwater content by the wet-bulk density of the GRAPE Special 2-Minute Count:

$$
\begin{aligned}
\text { porosity }(\%)= & \text { wet-bulk density }(\mathrm{g} / \mathrm{cc}) \\
& \times \text { wet-water content }(\%)
\end{aligned}
$$

Acoustic impedance was calculated as the product of the velocity and wet-bulk density:

$$
\begin{gathered}
\text { impedance }\left[\mathrm{g} /\left(\mathrm{cm}^{2} \mathrm{sec}\right)\right] \times 10^{5}=\text { velocity }(\mathrm{km} / \mathrm{sec}) \\
\times \text { wet-bulk density }(\mathrm{g} / \mathrm{cc})
\end{gathered}
$$

Impedance calculations utilized a sound velocity and a Special GRAPE 2-Minute Count wet-bulk density, which were measured on the same sample, perpendicular to the bedding unless otherwise noted in the tables in the Site Report chapters.

Impedance data allowed acoustic reflection coefficients $(R)$ to be calculated as follows:

$\mathrm{R}=\frac{\text { (impedance of Layer 2) }-(\text { impedance of Layer 1) }}{\text { (impedance of Layer 2) }+ \text { (impedance of Layer 1) }}$

where Layer 1 overlies Layer 2.

\footnotetext{
'Because of a procedure that required sampling of basalts after all basalt pieces were surface dried and labeled, even though copious amounts of water were squirted on the samples after labeling, one cannot be certain that these basalt samples were completely saturated.
} 
Oscilloscope Calibration and

Velocity Correction Factors

Two oscilloscopes were used on Leg 33: (1) the Deep Sea Drilling Project (DSDP) Tektronix 561A and (2) the Global Marine Inc. (GMI) Tektronix 453. The correction factors listed in Table 1 were applied to the calculated sound velocity for Holes 314, 315, 315A, 316, 317 through 317A (Core 31, Section 3), and 318, where the DSDP Tektronix 561A oscilloscope was used.

TABLE 1

Correction Factors $(K)$ for DSDP Tektronics 561A Oscilloscope

\begin{tabular}{cc}
\hline $\begin{array}{c}\text { Scope Setting } \\
\text { (micro-sec/cm) }\end{array}$ & $K$ \\
\hline 1.0 & Apparent velocity $\times 1.00776=$ true velocity \\
2.0 & Apparent velocity $\times 1.01981=$ true velocity \\
5.0 & Apparent velocity $\times 0.98759=$ true velocity \\
10.0 & Apparent velocity $\times 0.98835=$ true velocity \\
\hline
\end{tabular}

Samples from Hole 317A, Core 31, Section 4 through Hole $317 \mathrm{~B}$ had velocity measured using a second oscilloscope, the GMI Tektronix 453, because of equipment failure. A shipboard correction factor $(K)$ of 0.9880 for a "micro-sec/cm" setting of 2.0 was calculated for the GMI oscilloscope. This shipboard correction factor $(0.9880)$ was also used to calculate the velocity data published in this volume, which were measured with the GMI scope. Because of a shortage of time, the GMI oscilloscope was calibrated with as few measurements as possible.

The sound velocity correction factors are calculated by averaging numerous velocity measurements on the lucite, brass, and aluminum semistandards, assuming the true velocities are the Schreiber sound velocities listed is Table 2 (Boyce, 1973). Distilled water, whose acoustic velocities at given temperatures are known, is also used as a standard. Apparent velocity measurements are averaged for each semistandard for a given $\mu \mathrm{sec} / \mathrm{cm}$ setting on the oscilloscope. Deviations of the apparent velocity averages from the true (Schrieber) velocities of the semistandards listed in Table 2 are used to calculate a set of correction factors $(K)$ as follows:

average apparent velocity $(K)$

$$
=\text { true velocity of semistandards }
$$

Aboard ship a slightly different set of correction factors $(K)$ was calculated compared to a postcruise recalculation of the values $(K p)$ (see Tables 3 through $10)$, however the shipboard correction factor set (Table 1 ) is used in the calculation of the velocity data published in of this volume. The shipboard $(K)$ and postcruise $(K p)$ correction factors had differences of $0.024 \%$ and $0.065 \%$, for the DSDP and GMI oscilloscopes, respectively, and are not considered significant enough to warrant recalculation of the velocity data. The data from which the post-cruise calculation of the shipboard velocity correction factors $(K p)$ were made, are found in Tables 3 through 9 for the DSDP oscilloscope and Table 10 for the GMI oscilloscope.

\section{GRAVIMETRIC WET-WATER CONTENT TECHNIQUES}

Wet-water content is defined as the ratio, expressed as a percentage, of the "weight of sea water" to the "weight of wet-saturated sediment." The term "wet" modifying "water content" serves to distinguish this ratio from the other water content ratios published in the literature, such as "dry" water content, being the ratio expressed as a percentage of the weight of sea water to the weight of mineral solids, or "dry" sediment without pore water salts.

The wet-water content allows the sedimentary rock porosity to be calculated (ratio of the pore volume to the volume of the wet-saturated rock, expressed as a percentage) by using a "GRAPE Special 2-Minute Count" wet-bulk density (ratio of the weight of wet sediment to its volume, $\mathrm{g} / \mathrm{cc}$ ) which was determined on the same sample. The porosity is calculated using Equation 1, which uses a salt-corrected wet-water content value (discussed below). However, in order to correct this porosity value for salt content, the porosity value should be divided by the density of sea water $(1.025 \mathrm{~g} / \mathrm{cc})$. In the porosity scatter diagrams all that is necessary to have true porosity is to reduce the porosity scale by a ratio of $1: 1.025$.

The physical sampling was done (1) by using a syringe on some soft sediments, and (2) by simply taking a chunk from more coherent sedimentary rocks. The syringe has a 1-cc volume and has the end cut off and sharpened so that the outer edge of the syringe tip is beveled so that the syringe cylinder's leading edge is sharp and flush with the inside diameter. When a soft undisturbed (visible undistorted bedding) sediment was sampled, the syringe was used in the same manner as a deep-sea piston corer. The syringe is placed perpendicular to the cleaned surface of the soft sediment of a split core with the end of the syringe piston resting on the sediment surface. The piston is held stationary while the syringe cylinder is slowly pushed into the sediment. The syringe is cut from the sediment with a spatula so that the syringe can be withdrawn with a minimum of suction. The end of the syringe is then wrapped with a film of plastic, which is self-adhesive and seals the sediment inside the syringe. The syringe is then placed in a box with a wet sponge, and the box is kept in a refrigerator (a few degrees above freezing) until the sample is to be weighed.

Other samples were collected by simply using a spatual and cutting a chunk from a stiff sediment, or a hammer and chisel to get a small uncontaminated chunk of hard rock. These chunks are placed into small plastic vials with dampened tissues (not touching the samples). The vials are capped and sealed with tape, and then placed in a refrigerator until they are weighed.

When weighing, the sample is placed in a preweighed aluminum tray and the wet-saturated sample is weighed. Then the sample is dried $24 \mathrm{hr}$ at $110^{\circ} \mathrm{C}$ and cooled at least $2 \mathrm{hr}$ in a desiccator before the dried sample is weighed. The aluminum tray plus the sample cannot weigh more than $1 \mathrm{~g}$, which is the maximum weight which can be accurately weighed on the Cahn Gram Electro Balance at sea. Each weighing is accurate within 
TABLE 2

Predetermined Sound Velocities of Lucite, Brass, and

Aluminum Semistandards as Listed in Boyce (1973)

\begin{tabular}{llll}
\hline & \multicolumn{1}{c}{ Lucite } & \multicolumn{1}{c}{ Brass } & \multicolumn{1}{c}{ Aluminum } \\
\hline Boyce (1973) & $2.741 \mathrm{~km} / \mathrm{sec}$ & $4.506 \mathrm{~km} / \mathrm{sec}$ & $6.293 \mathrm{~km} / \mathrm{sec}$ \\
& $( \pm 0.84 \%)$ & $( \pm 0.45 \%)$ & $( \pm 1.29 \%)$ \\
Schrieber $^{\mathrm{a}}$ & $2.745 \mathrm{~km} / \mathrm{sec}$ & $4.529 \mathrm{~km} / \mathrm{sec}$ & $6.295 \mathrm{~km} / \mathrm{sec}$ \\
& $( \pm 0.006 \mathrm{~km} / \mathrm{sec})$ & $( \pm 0.004 \mathrm{~km} / \mathrm{sec})$ & $( \pm 0.008 \mathrm{~km} / \mathrm{sec})$ \\
\hline
\end{tabular}

${ }^{a}$ Lamont-Doherty Geological Observatory, personal communication, 1971. Schreiber used the modified pulse transmission method (Mottaboni and Schreiber, 1967).

TABLE 3

Uncorrected Velocities $(\mathrm{km} / \mathrm{sec})$ Through Aluminum Semistandards Used for the Partial Calibration $\left(K^{\prime}\right)$ of Each $\mu \mathrm{sec} / \mathrm{cm}$ Setting on the DSDP Oscilloscope

\begin{tabular}{|c|c|c|c|c|c|c|c|c|}
\hline \multirow{2}{*}{$\begin{array}{c}\mu \mathrm{sec} / \mathrm{cm} \\
\text { Thickness of } \\
\text { Semistandard }\end{array}$} & \multicolumn{2}{|c|}{1.0} & \multicolumn{2}{|c|}{2.0} & \multicolumn{2}{|c|}{5.0} & \multicolumn{2}{|c|}{10.0} \\
\hline & $2.54 \mathrm{~cm}$ & $5.00 \mathrm{~cm}$ & $2.54 \mathrm{~cm}$ & $5.00 \mathrm{~cm}$ & $2.54 \mathrm{~cm}$ & $5.00 \mathrm{~cm}$ & $2.54 \mathrm{~cm}$ & $5.00 \mathrm{~cm}$ \\
\hline 2 November 1973 & $\begin{array}{l}* * \\
6.258 \\
6.251 \\
6.197\end{array}$ & $\begin{array}{l}* * * \\
6.230 \\
6.237 \\
6.268\end{array}$ & $\begin{array}{l}* \\
6.081 \\
6.024 \\
6.111\end{array}$ & $\begin{array}{l}* * \\
6.176 \\
6.160 \\
6.160\end{array}$ & & $\begin{array}{l}* \\
6.325 \\
6.345 \\
6.288\end{array}$ & & \\
\hline 3 November 1973 & $\begin{array}{l}6.172 \\
6.157 \\
6.248\end{array}$ & $\begin{array}{l}6.287 \\
6.244 \\
6.284\end{array}$ & $\begin{array}{l}5.984 \\
6.157 \\
6.040\end{array}$ & $\begin{array}{l}6.095 \\
6.058 \\
6.169\end{array}$ & & $\begin{array}{l}6.418 \\
6.423 \\
6.424\end{array}$ & & \\
\hline 4 November 1973 & $\begin{array}{l}6.210 \\
6.208 \\
6.187\end{array}$ & $\begin{array}{l}6.245 \\
6.225 \\
6.218\end{array}$ & $\begin{array}{l}6.038 \\
6.009 \\
5.981\end{array}$ & $\begin{array}{l}6.124 \\
6.146 \\
6.139\end{array}$ & & $\begin{array}{l}6.483 \\
6.443 \\
6.344\end{array}$ & & \\
\hline Mean velocity & 6.210 & 6.249 & 6.047 & 6.136 & & 6.388 & & \\
\hline Range (\%) & $\begin{array}{r}-0.853 \\
+0.773\end{array}$ & $\begin{array}{r}-0.496 \\
+0.608\end{array}$ & $\begin{array}{l}-1.091 \\
+0.182\end{array}$ & $\begin{array}{l}-1.271 \\
+0.652\end{array}$ & & $\begin{array}{l}-1.565 \\
+1.487\end{array}$ & & \\
\hline$K^{\prime \mathrm{a}}$ & 1.01369 & 1.00736 & 1.04101 & 1.02591 & & 0.98544 & & \\
\hline
\end{tabular}

Note: The best precision of the data occurs when using the full range of the "cm-delay" dial on the oscilloscope: $* * *=$ best use of $\mathrm{cm}$-delay dial: 0 to 10.0 range; $* *=$ fair use of $\mathrm{cm}$-delay dial: 0 to 6.0 range; $*=$ poor use of $\mathrm{cm}$ delay dial: 0 to 3.0 range.

a (Mean velocity) $K^{\prime}=$ true velocity $=6.295$.

TABLE 4

Uncorrected Velocities $(\mathrm{km} / \mathrm{sec})$ Through Brass Semistandards Used for the Partial Calibration $\left(K^{\prime}\right)$ of Each $\mu \mathrm{sec} / \mathrm{cm}$ Setting on the DSDP Oscilloscope

\begin{tabular}{|c|c|c|c|c|c|c|c|c|}
\hline$\mu \mathrm{sec} / \mathrm{cm}$ & \multicolumn{2}{|c|}{1.0} & \multicolumn{2}{|c|}{2.0} & \multicolumn{2}{|c|}{5.0} & \multicolumn{2}{|c|}{10.0} \\
\hline Semistandard & $\begin{array}{l}2.54 \mathrm{~cm} \\
* *\end{array}$ & $5.00 \mathrm{~cm}$ & $\begin{array}{l}2.54 \mathrm{~cm} \\
*\end{array}$ & $\begin{array}{l}5.00 \mathrm{~cm} \\
* *\end{array}$ & $2.54 \mathrm{~cm}$ & $\begin{array}{l}5.00 \mathrm{~cm} \\
*\end{array}$ & $2.54 \mathrm{~cm}$ & $\begin{array}{l}5.00 \mathrm{~cm} \\
*\end{array}$ \\
\hline 2 November 1973 & $\begin{array}{l}4.439 \\
4.484 \\
4.459\end{array}$ & & $\begin{array}{l}4.367 \\
4.405 \\
4.367\end{array}$ & $\begin{array}{l}4.413 \\
4.497 \\
4.419\end{array}$ & & $\begin{array}{l}4.599 \\
4.581 \\
4.579\end{array}$ & & 4.625 \\
\hline 3 November 1973 & $\begin{array}{l}4.455 \\
4.455 \\
4.455\end{array}$ & & $\begin{array}{l}4.409 \\
4.400 \\
4.436\end{array}$ & $\begin{array}{l}4.411 \\
4.371 \\
4.463\end{array}$ & & $\begin{array}{l}4.544 \\
4.518 \\
4.528\end{array}$ & & $\begin{array}{l}4.602 \\
4.519 \\
4.623\end{array}$ \\
\hline 4 November 1973 & $\begin{array}{l}4.469 \\
4.509 \\
4.457\end{array}$ & & $\begin{array}{l}4.479 \\
4.424 \\
4.424\end{array}$ & $\begin{array}{l}4.344 \\
4.458 \\
4.419\end{array}$ & & $\begin{array}{l}4.545 \\
4.557 \\
4.576\end{array}$ & & $\begin{array}{l}4.565 \\
4.650 \\
4.586\end{array}$ \\
\hline Mean velocity & 4.465 & & 4.412 & 4.422 & & 4.558 & & 4.596 \\
\hline Range (\%) & $\begin{array}{l}-0.582 \\
+0.985\end{array}$ & & $\begin{array}{r}-0.020 \\
+1.519\end{array}$ & $\begin{array}{l}-1.764 \\
+1.696\end{array}$ & & $\begin{array}{l}-0.878 \\
+0.900\end{array}$ & & $\begin{array}{l}-1.675 \\
+1.175\end{array}$ \\
\hline$K^{\prime \mathrm{a}}$ & 1.01433 & & 1.02652 & 1.02420 & & 0.99364 & & 0.98542 \\
\hline
\end{tabular}

Note: The best precision of the data occurs when using the full range of the "cm-delay" dial on the oscilloscope: ${ }^{* * *}=$ best use of $\mathrm{cm}$-delay dial: 0 to 10.0 range; $* *=$ fair use of $\mathrm{cm}$-delay dial: 0 to 6.0 range; $*=$ poor use of cmdelay dial: 0 to 3.0 range.

a $\left(\right.$ Mean velocity) $K^{\prime}=$ true velocity $=4.529 \mathrm{~km} / \mathrm{sec}$. 
$\pm 1 \%$ depending on the sea state (Table 11). Therefore the precision of the wet-water content is about $\pm 2 \%$ (absolute).

The following gravimetric definitions and calculations are discussed in two groups: First is the wet-water content calculated from the gravimetric data without correcting for the difference in weights and volume between sea water and distilled water, and not correcting for the dried salt from the interstitial water that is included in the dry mineral weights. The second group of calculations go through the derivations and applications of salt corrections assuming a sea-water salinity of $35 \mathrm{ppt}$ and its density at $21^{\circ} \mathrm{C}$. All of the following dry weights and evaporated water weights are by definition the result of drying at $110^{\circ} \mathrm{C}$ for $24 \mathrm{hr}$ and cooling in a desiccator for at least $2 \mathrm{hr}$ before weighing. All mention of wet sediment in this text assumes $100 \%$ saturation by sea water.

\section{Definitions and Equations \\ Without Salt Corrections}

In the definitions and other equations below the following parameters will be abbreviated as listed:

$\begin{array}{ll}\text { dry } & \text { dry } \\ \text { equation } & \text { eq. } \\ \text { evaporated } & \text { evap. } \\ \text { salts } & \text { salt } \\ \text { sea water } & \text { sea wat. } \\ \text { sediment } & \text { sed. } \\ \text { solids } & \text { solids } \\ \text { water } & \text { wat. } \\ \text { weight } & \text { wt. } \\ \text { wet } & \text { wet }\end{array}$

The following calculations are without salt corrections.

Wet-Water Content Without Salt Correction: Wetwater content is defined as the weight of sea water in the saturated sediment divided by the weight of the saturated wet sediment, which is expressed as a percentage.

$$
\text { wet-water content }(\%)=\left(\frac{\text { wt. sea wat. }}{\text { wt. wet sed. }}\right)(100)
$$

Gravimetric data and calculations without salt correction follow:

wet-water content (\%) (without salt correction)

$$
=\left[\frac{(\text { wt. wet sed. })-(\text { wt. dry sed. }+ \text { salt })}{\text { wt. wet sed. }}\right]
$$

wet-water content (\%)

(without salt

correction)

$$
=\left[\frac{\text { (wt. evap. wat. })}{\text { (wt. wet sed.) }}\right](100
$$

\section{Definitions, Gravimetric Data, and Equations with Salt Corrections}

Leg 33 wet-water content values have salt corrections applied as follows:

Salt Corrections: This group of calculations include derivations of salt corrections for differing weights and volumes between sea water and distilled water, and corrections for interstitial water salt that is included in the dry sediment weights. This derivation assumes that the interstitial water is similar to sea water and has not undergone significant diagenetic changes. These salt corrections are based on interstitial water salinities of 35 ppt and follow the premises put forth in Hamilton (1971), who discusses these methods of salt correction and demonstrates what he believes are practical correction factors.

The following theoretical salt adjustments are not absolutely correct as one must keep in mind the difference between the sea-water salt's volume and weight when dried at $110^{\circ} \mathrm{C}$ for $24 \mathrm{hr}$, and compared to its volume and weight resulting from the temperature and conditions that define salinity. Salinity was defined as "the weight in grams (in vacuo) of the solids that can be obtained from $1 \mathrm{~kg}$ of sea water (likewise measured in vacuo) when all the carbonate has been converted to oxides, the bromine and iodine replaced by chlorine, all organic matter oxidized and the remainder dried at $480^{\circ} \mathrm{C}$ to constant weight" (Barnes, 1959, p. 85). Salinities are reported as grams per kilogram of sea water (parts per thousand). However, for most practical purposes the following approximate theoretical salt corrections should suffice.

The present salt corrections are based upon the following theoretical salt corrections discussed in Hamilton (1971):

$$
\text { weight sea water }=\frac{\text { wt. evap. wat. }}{1-\text { salt content }}
$$

note,

$$
\text { salinity }=35 \mathrm{ppt}=\frac{35 \mathrm{~g}}{1000 \mathrm{~g}}=0.035
$$

therefore,

$$
(1-\text { salt content })=(1.000-0.035)=0.965
$$

thus,

$$
\text { "weight sea water" }=\frac{\text { wt. evap. wat. }}{0.965}
$$

Wet-Water content with Salt Correction: Wet-water content is the weight of sea water in a saturated wet sediment divided by the weight of the wet-saturated sediment. Gravimetric data and calculations without salt correction are shown in Equation 7. In order to correct this equation for salt content, all that is necessary is to substitute Equation 11 for the weight evaporated water to obtain the actual weight of sea water. Therefore wetwater content with salt corrections is calculated as:

$\begin{gathered}\text { wet-water content }(\%) \\ \text { (with salt correction) }\end{gathered}=\left[\frac{\frac{\text { wt. evap. wat. }}{0.965}}{\text { wt. wet sed. }}\right]$ 
For ease of calculation this equation can be rearranged as follows:

wet-water content (\%) (with salt correction)

$$
\begin{aligned}
& =1.0363 \text { (wet-water content without } \\
& \text { salt correction) }
\end{aligned}
$$

\section{DSDP LEG 33 PROCEDURES \\ USING THE GAMMA RAY ATTENUATION POROSITY EVALUATOR (GRAPE)}

\section{Introduction}

The Deep Sea Drilling Project has used gamma ray attenuation techniques to measure the wet-bulk density, which is defined here as weight per unit volume expressed as grams per cubic centimeter, of sediments and rocks. Aboard Glomar Challenger is a device called Gamma Ray Attenuation Porosity Evaluator (hereafter referred to by its acronym GRAPE) which determines the wet-bulk density of the sediment and rock. The GRAPE was developed and described by Evans (1965) of Marathon Oil Company, and its geologic applications were developed directly by Evans (1965) and Harms and Choquette (1965), however, basic principles involved were also studied independently by Tittman and Wahl (1965), Wahl et al. (1964), and Schlumberger (1972). Earlier studies independent of the GRAPE and DSDP are found in the reference lists of Evans (1965), Harms and Choquette (1965), and Tittman and Wahl (1965), and later independent studies have been by Keller (1965), Preiss et al. (1968), Brier et al. (1969), and Meyers et al. (1973), and others.

The main problem with gamma ray attenuation measurements for density is that all minerals do not attenuate gamma rays at the same rate, for example, quartz and water are different by $10 \%$. Therefore, when using gamma attenuation to determine the true wet-bulk density of a sample with various minerals combined such as quartz and water, then the approximate density determined by the GRAPE must be adjusted to give true density. These problems plus geometric sampling problems and miscellaneous problems with the general methods are what the following techniques are concerned with.

Geologic application of the GRAPE to DSDP cores began on Legs 1 and 2 of the DSDP. These legs had to use the GRAPE data as it was presented aboard the ship, as these legs predated the shore-based computer processing of the GRAPE data. From Legs 1 and 2 it is not completely clear how the GRAPE was calibrated, or if the density values published are true or the Evans (1965) corrected (calculated with a quartz attenuation coefficient) wet-bulk density. However, the aluminum and water standards in liners, which were the same diameter as the soft cores, were processed with the cores, which should allow the data to be manipulated.

Data from Leg 3 through 11 were the first to be processed through the shore-based computer facilities at Scripps Institution of Oceanography. This technique and its problems are briefly described in Boyce (1973).

An iteration technique derived by Whitmarsh (1971) was used on DSDP Legs 12 through 28 . The resulting data from the iteration technique are identical (for practical purposes) to the Leg 3 technique if the same parameters are used. This technique is described in Whitmarsh (1971) and Boyce (1973) which contain discussions of the basic principles as applied to the DSDP GRAPE data. Boyce (1973) has a typographical error on page 118 , in step 2 of the Whitmarsh iteration, where " $\rho_{w t}$ " should read " $\rho_{w g}$." In addition, on page 1120 , " $100 \mathrm{~A}=\mathrm{D}(100-\mathrm{x})-\mathrm{Sx}$ " should read "100A = D (100x) + Sx."

TABLE 5

Uncorrected Velocities (km/sec) Through Lucite Semistandards Used for the Partial Calibration

\begin{tabular}{|c|c|c|c|c|c|c|c|c|}
\hline \multirow{2}{*}{$\begin{array}{c}\mu \mathrm{sec} / \mathrm{cm} \\
\text { Thickness of } \\
\text { Semistandards }\end{array}$} & \multicolumn{2}{|c|}{1.0} & \multicolumn{2}{|c|}{2.0} & \multicolumn{2}{|c|}{5.0} & \multicolumn{2}{|c|}{10.0} \\
\hline & $2.54 \mathrm{~cm}$ & $5.00 \mathrm{~cm}$ & $2.54 \mathrm{~cm}$ & $5.00 \mathrm{~cm}$ & $2.54 \mathrm{~cm}$ & $5.00 \mathrm{~cm}$ & $2.54 \mathrm{~cm}$ & $5.00 \mathrm{~cm}$ \\
\hline & $* * *$ & & $* *$ & $* * *$ & & $* *$ & & $*$ \\
\hline 2 November 1973 & $\begin{array}{l}2.725 \\
2.728 \\
2.741\end{array}$ & & $\begin{array}{l}2.670 \\
2.677 \\
2.672\end{array}$ & $\begin{array}{l}2.697 \\
2.708 \\
2.715\end{array}$ & & $\begin{array}{l}2.782 \\
2.786 \\
2.786\end{array}$ & & $\begin{array}{l}2.771 \\
2.786 \\
2.786\end{array}$ \\
\hline 3 November 1973 & $\begin{array}{l}2.732 \\
2.732 \\
2.732\end{array}$ & & $\begin{array}{l}2.730 \\
2.713 \\
2.711\end{array}$ & $\begin{array}{l}2.704 \\
2.708 \\
2.702\end{array}$ & & $\begin{array}{l}2.784 \\
2.788 \\
2.774\end{array}$ & & $\begin{array}{l}2.756 \\
2.756 \\
2.756\end{array}$ \\
\hline 4 November 1973 & $\begin{array}{l}2.749 \\
2.741 \\
2.741\end{array}$ & & $\begin{array}{l}2.701 \\
2.704 \\
2.699\end{array}$ & $\begin{array}{l}2.691 \\
2.684 \\
2.682\end{array}$ & & $\begin{array}{l}2.785 \\
2.782 \\
2.782\end{array}$ & & $\begin{array}{l}2.767 \\
2.782 \\
2.790\end{array}$ \\
\hline Mean velocity & 2.736 & & 2.697 & 2.699 & & 2.783 & & 2.772 \\
\hline Range (\%) & $\begin{array}{l}-0.402 \\
+0.475\end{array}$ & & $\begin{array}{l}-1.001 \\
+1.223\end{array}$ & $\begin{array}{l}-0.630 \\
+0.593\end{array}$ & & $\begin{array}{l}-0.324 \\
+0.180\end{array}$ & & $\begin{array}{r}-0.577 \\
+0.649\end{array}$ \\
\hline$K^{\prime \mathrm{a}}$ & 1.00329 & & 1.01780 & 1.01704 & & 0.98635 & & 0.99026 \\
\hline
\end{tabular}
$\left(K^{\prime}\right)$ of Each $\mu \mathrm{sec} / \mathrm{cm}$ Setting on the DSDP Oscilloscope

Note: The best precision of the data occurs when using the full range of the "cm-delay" dial on the oscilloscope: ${ }^{* * *}=$ best use of cm-delay dial: 0 to 10.0 range; ${ }^{* *}=$ fair use of $\mathrm{cm}$-delay dial: 0 to 6.0 range; ${ }^{*}=$ poor use of $\mathrm{cm}$ delay dial: 0 to 3.0 range.

${ }^{\mathrm{a}}$ (Mean velocity) $K^{\prime}=$ true velocity $=2.745 \mathrm{~km} / \mathrm{sec}$. 
TABLE 6

Uncorrected Velocities $(\mathrm{km} / \mathrm{sec})$ Through Distilled Water $\left(22^{\circ} \mathrm{C}\right)$ Semistandard Used for the Partial Calibration of $\left(K^{\prime}\right)$ of Each $\mu \mathrm{sec} / \mathrm{cm}$ Setting on the DSDP Oscilloscope

\begin{tabular}{|c|c|c|c|c|c|c|c|c|}
\hline \multirow{2}{*}{$\begin{array}{c}\mu \mathrm{sec} / \mathrm{cm} \\
\text { Thickness of } \\
\text { Semistandards }\end{array}$} & \multicolumn{2}{|c|}{1.0} & \multicolumn{2}{|c|}{2.0} & \multicolumn{2}{|c|}{5.0} & \multicolumn{2}{|c|}{10.0} \\
\hline & $1.0 \mathrm{~cm}$ & $2.0 \mathrm{~cm}$ & $1.0 \mathrm{~cm}$ & $2.0 \mathrm{~cm}$ & $1.0 \mathrm{~cm}$ & $2.0 \mathrm{~cm}$ & $1.0 \mathrm{~cm}$ & $2.0 \mathrm{~cm}$ \\
\hline & $* * *$ & & ** & $* * *$ & * & * & & * \\
\hline 2 November 1973 & $\begin{array}{l}1.499 \\
1.485 \\
1.486\end{array}$ & & $\begin{array}{l}1.462 \\
1.468 \\
1.477\end{array}$ & $\begin{array}{l}1.470 \\
1.476 \\
1.475\end{array}$ & $\begin{array}{l}1.515 \\
1.522 \\
1.515\end{array}$ & $\begin{array}{l}1.515 \\
1.511 \\
1.518\end{array}$ & & $\begin{array}{l}1.515 \\
1.515 \\
1.504\end{array}$ \\
\hline Mean velocity & 1.490 & & 1.469 & 1.474 & 1.517 & 1.515 & & 1.511 \\
\hline Range (\%) & $\begin{array}{l}+0.604 \\
-0.336\end{array}$ & & $\begin{array}{l}+0.613 \\
-0.477\end{array}$ & $\begin{array}{l}+0.136 \\
-0.271\end{array}$ & $\begin{array}{l}+0.330 \\
-0.132\end{array}$ & $\begin{array}{l}+0.198 \\
-0.264\end{array}$ & & $\begin{array}{l}+0.265 \\
-0.463\end{array}$ \\
\hline$K^{\prime^{\mathrm{a}}}$ & 1.00067 & & 1.01498 & 1.01153 & 0.98286 & 0.98416 & & 0.98676 \\
\hline
\end{tabular}

Note: The best precision of the data occurs when using the full range of the "cm-delay" dial on the oscilloscope: $* * *=$ best use of $\mathrm{cm}$-delay dial: 0 to 10.0 range; $* *=$ fair use of $\mathrm{cm}$-delay dial: 0 to 6.0 range; $*=$ poor use of cmdelay dial: 0 to 3.0 range.

a (Mean velocity) $K^{\prime}=$ true velocity $=1.491 \mathrm{~km} / \mathrm{sec}$.

TABLE 7

Uncorrected Velocities $(\mathrm{km} / \mathrm{sec})$ Through Distilled Water $\left(21^{\circ} \mathrm{C}\right)$ Semistandard Used for the Partial Calibration $\left(K^{\prime}\right)$ of Each $\mu \mathrm{sec} / \mathrm{cm}$ Setting on the DSDP Oscilloscope

\begin{tabular}{|c|c|c|c|c|c|c|c|c|}
\hline \multirow{2}{*}{$\begin{array}{c}\mu \mathrm{sec} / \mathrm{cm} \\
\text { Thickness of } \\
\text { Semistandards }\end{array}$} & \multicolumn{2}{|c|}{1.0} & \multicolumn{2}{|c|}{2.0} & \multicolumn{2}{|c|}{5.0} & \multicolumn{2}{|c|}{10.0} \\
\hline & $1.0 \mathrm{~cm}$ & $2.0 \mathrm{~cm}$ & $1.0 \mathrm{~cm}$ & $2.0 \mathrm{~cm}$ & $1.0 \mathrm{~cm}$ & $2.0 \mathrm{~cm}$ & $1.0 \mathrm{~cm}$ & $2.0 \mathrm{~cm}$ \\
\hline & $* *$ & & $* *$ & $* * *$ & $*$ & $*$ & & $*$ \\
\hline 3 November 1973 & $\begin{array}{l}1.486 \\
1.496 \\
1.469\end{array}$ & & $\begin{array}{l}1.468 \\
1.469 \\
1.467\end{array}$ & $\begin{array}{l}1.465 \\
1.470 \\
1.465\end{array}$ & $\begin{array}{l}1.503 \\
1.494 \\
1.503\end{array}$ & $\begin{array}{l}1.512 \\
1.521 \\
1.507\end{array}$ & & $\begin{array}{l}1.498 \\
1.504 \\
1.515\end{array}$ \\
\hline 4 November 1973 & $\begin{array}{l}1.491 \\
1.498 \\
1.506\end{array}$ & & & $\begin{array}{l}1.468 \\
1.466 \\
1.471\end{array}$ & & $\begin{array}{l}1.498 \\
1.504 \\
1.512\end{array}$ & & $\begin{array}{l}1.504 \\
1.504 \\
1.487\end{array}$ \\
\hline Mean velocity & 1.491 & & 1.468 & 1.468 & 1.500 & 1.509 & & 1.502 \\
\hline Range (\%) & $\begin{array}{l}+1.006 \\
-1.456\end{array}$ & & $\begin{array}{l}+0.068 \\
-0.068\end{array}$ & $\begin{array}{l}+0.204 \\
-0.204\end{array}$ & $\begin{array}{l}+0.200 \\
-0.400\end{array}$ & $\begin{array}{l}+0.795 \\
-0.729\end{array}$ & & $\begin{array}{l}+0.866 \\
-0.999\end{array}$ \\
\hline$K^{\prime \mathrm{a}}$ & 0.99798 & & 1.01362 & 1.01362 & 0.99200 & 0.98608 & & 0.99068 \\
\hline
\end{tabular}

Note: The best precision of the data occurs when using the full range of the "cm-delay" dial on the oscilloscope: $* * *$ = best use of $\mathrm{cm}$-delay dial: 0 to 10.0 range; $* *=$ fair use of $\mathrm{cm}$-delay dial: 0 to 6.0 range; $*$ poor use of $\mathrm{cm}$ delay dial: 0 to 3.0 range.

a (Mean velocity) $K^{\prime}=$ true velocity $=1.488 \mathrm{~km} / \mathrm{sec}$.

TABLE 8

Calculation of the Mean Distilled Water $\left(21^{\circ} \mathrm{C}\right.$ and $\left.22^{\circ} \mathrm{C}\right)$ Velocity Correction Factors $\left(K^{\prime}\right)$ Used to Partially Calibrate Each $\mu \mathrm{sec} / \mathrm{cm}$ Setting on the DSDP Oscilloscope

\begin{tabular}{|c|c|c|c|c|c|c|c|c|}
\hline \multirow{2}{*}{$\begin{array}{c}\mu \mathrm{sec} / \mathrm{cm} \\
\text { Thickness of } \\
\text { Semistandards }\end{array}$} & \multicolumn{2}{|c|}{1.0} & \multicolumn{2}{|c|}{2.0} & \multicolumn{2}{|c|}{5.0} & \multicolumn{2}{|c|}{10.0} \\
\hline & $1.0 \mathrm{~cm}$ & $2.0 \mathrm{~cm}$ & $1.0 \mathrm{~cm}$ & $2.0 \mathrm{~cm}$ & $1.0 \mathrm{~cm}$ & $2.0 \mathrm{~cm}$ & $1.0 \mathrm{~cm}$ & $2.0 \mathrm{~cm}$ \\
\hline $21^{\circ}$ & 0.99798 & & 1.01362 & $1.01362^{\mathrm{a}}$ & 0.99200 & $0.98608^{a}$ & & $0.99068^{a}$ \\
\hline $21^{\circ}$ & 0.99798 & & & $1.01362^{\mathrm{a}}$ & & $0.98608^{a}$ & & $0.99068^{a}$ \\
\hline $22^{\circ}$ & 1.00067 & & 1.01498 & 1.01153 & 0.98286 & 0.98416 & & 0.98676 \\
\hline Mean $K^{\prime}$ & 0.99888 & & 1.01430 & 1.01292 & 0.98743 & 0.98544 & & 0.98937 \\
\hline
\end{tabular}

${ }^{\text {a }}$ Two values of $K^{\prime}$ at $21^{\circ} \mathrm{C}$ are used, in order to weigh the mean $K^{\prime}$ relative to the number of velocity measurements (6) at $21^{\circ} \mathrm{C}$ to those (3) at $22^{\circ} \mathrm{C}$. 
The greatest drawback in the publication of the DSDP GRAPE density data derived from the Leg 3 and Leg 12 techniques is that they were designed for soft sediment which completely filled the liners, and which were the same size as the standards. Problems have arisen, as discussed in Boyce (1973), where hard rocks are cored which have smaller diameters than the standards or core liners used. Adjustments for these geometric problems have not been generally applied except in a few DSDP legs. Investigators interested in finding out if a particular hole, core, section, or interval had geometric adjustments can consult with the DSDP computer group.

The purpose of the present paper is (1) to describe new DSDP gamma-ray attenuation digital equipment and data collection techniques; (2) to show derivation of new equations for data reduction which can be done with simple formulas which have been used since Leg 29; (3) to describe how these formulas were used on DSDP Legs 3 through 11 GRAPE data and their limitations; (4) to describe limitations to look for in all previous DSDP GRAPE data; and (5) to study how to manipulate any previous DSDP GRAPE data, and if possible, obtain more accurate density values.

\section{GRAPE System}

Basically, the GRAPE system consists of a drive device to move geologic material (as cores) between a shielded gamma-ray source $\left({ }^{133} \mathrm{Ba}\right.$ using the 0.3 and $0.359 \mathrm{MeV}$ energy levels) and a shielded scintillation detector. The system also includes an analog computer which immediately calculates "corrected" (using a single attenuation coefficient, theoretically that of quartz) wetbulk density based on the attenuation of gamma rays through the geological material and other measured parameters. The GRAPE Analog equipment (Evans, 1965) measured, calculated, and plotted "corrected" wet bulk density on an analog graph. The GRAPE operated in a continuous mode with the "corrected" density being continually measured along the length of a core. The basic setup of the GRAPE equipment is discussed in detail in Evans (1965), but the DSDP application and dial settings are discussed in Boyce (1973) and will not be discussed here.

DSDP has added more electronic equipment (see Appendices A, D, and E), which record gamma counts (2-second period) on magnetic tape as the core is continually scanned along its length. (By Leg 42 two mechanical arms will measure the gamma-ray path length and record it also on the magnetic tape.) The main purpose of the raw magnetic tape data was to make easier computer handling. However, there are other advantages, as we have the capability of counting for a 2-minute period in a static mode on a single small sample. The 2-minute counting period is advantageous as the longer counting times allow greatly increased precision. By taking a wet-water content sample, the porosity of the rock can be calculated from the wet-bulk density value. The single small samples are extremely advantageous because they allow close intercorrelation of the physical properties which can be measured on the same sample, for example, sound velocity, wet-bulk density, and porosity. These small density samples are called the "GRAPE 2-Minute Special" wet-bulk density.

The basic theory of the gamma-ray attenuation will be presented, followed by the "GRAPE 2-Minute Special" wet-bulk density techniques, and the GRAPE magnetic tape analog techniques. The following discussions will be applicable to old and new DSDP techniques as they all have identical problems with attenuation coefficients, grain densities, and diameter (gamma-ray path length) measurements.

\section{Theory}

The basic theory of gamma-ray attenuation is discussed in Evans (1965), Harms and Choquette (1965), Evans and Cotterel (1970), and Brier, et al. (1969). Preiss (1968) has an excellent discussion of the attenuation theory, although his units and other parameters differ from those of Evans (1965). I suggest for anyone desiring to use or study the theory in detail that they consult the papers cited above. The present paper will only dis-

TABLE 9

Calculation of the Final (postcruise) Mean Velocity Correction Factors $(K p)$ for Each $\mu \mathrm{sec} / \mathrm{cm}$ Setting on the DSDP Oscilloscope (Velocity-Correction Factors $\left(K^{\prime}\right)$ from Tables 3 through 8 )

\begin{tabular}{|c|c|c|c|c|c|c|c|c|}
\hline \multirow{2}{*}{$\begin{array}{c}\mu \mathrm{sec} / \mathrm{cm} \\
\text { Thickness of } \\
\text { Semistandards }\end{array}$} & \multicolumn{2}{|c|}{1.0} & \multicolumn{2}{|c|}{2.0} & \multicolumn{2}{|c|}{5.0} & \multicolumn{2}{|c|}{10.0} \\
\hline & $\leqslant 2.54 \mathrm{~cm}$ & $5.00 \mathrm{~cm}$ & $\leqslant 2.54 \mathrm{~cm}$ & $5.00 \mathrm{~cm}$ & $\leqslant 2.54 \mathrm{~cm}$ & $5.00 \mathrm{~cm}$ & $\leqslant 2.54 \mathrm{~cm}$ & $5.00 \mathrm{~cm}$ \\
\hline Water $2.0 \mathrm{~cm}$ & & & $1.01292 * * *$ & & $0.98544 *$ & & & \\
\hline Water $1.0 \mathrm{~cm}$ & $0.99888 * *$ & & $1.01430 * *$ & & 0.98743 & & & $0.98937^{*}$ \\
\hline Lucite & $1.00329 * * *$ & & $1.01780 * *$ & $1.01704 * * *$ & & $0.98635 * *$ & & $0.99026 *$ \\
\hline Brass & $1.01433^{* *}$ & & $1.02652 *$ & $1.02420^{* *}$ & & $0.99364 *$ & & $0.98542^{*}$ \\
\hline Aluminum & $1.01369 * *$ & $1.00736 * * *$ & $\begin{array}{l}\left(1.04101^{*}\right) \\
\text { Deleted }\end{array}$ & $1.02591^{* *}$ & & $0.98544^{*}$ & & \\
\hline Postcruise & \multirow{2}{*}{\multicolumn{2}{|c|}{1.00751}} & & & & & & \\
\hline $\begin{array}{l}\text { Recalculated } \\
\text { mean } K p\end{array}$ & & & \multicolumn{2}{|c|}{1.01981} & \multicolumn{2}{|c|}{0.98766} & \multicolumn{2}{|c|}{0.98835} \\
\hline $\begin{array}{l}\text { Shipboard } \\
\text { Mean } K\end{array}$ & \multicolumn{2}{|c|}{1.00776} & \multicolumn{2}{|c|}{1.01981} & \multicolumn{2}{|c|}{0.98759} & \multicolumn{2}{|c|}{0.98835} \\
\hline
\end{tabular}

Note: The best precision of the data occurs when using the full range of the "cm-delay" dial: $* * *=$ best use of the cm-delay dial: 0 to 10.0 range; ${ }^{* *}=$ fair use of the cm-delay dial: 0 to 6.0 range; ${ }^{*}=$ poor use of the cm-delay dial: 0 to 3.0 range. 
TABLE 10

Uncorrected Velocity Values ( $\mathrm{km} / \mathrm{sec}$ ) and Final Calculation of (postcruise) the Velocity Correction Factor $(K p)$ for the $2.0 \mu \mathrm{sec} / \mathrm{cm}$ Setting on the Global Marine Inc. Tektronix 453 Oscilloscope

\begin{tabular}{|c|c|c|c|c|c|c|}
\hline \multirow[t]{2}{*}{$\begin{array}{l}\text { Thickness of } \\
\text { Semistandards }\end{array}$} & \multicolumn{3}{|c|}{$\begin{array}{l}2.54 \mathrm{~cm} \\
\text { Lucite }\end{array}$} & \multirow{2}{*}{$\begin{array}{c}5.00 \mathrm{~cm} \\
\text { Lucite }\end{array}$} & \multicolumn{2}{|l|}{$\begin{array}{c}5.00 \mathrm{~cm} \\
\mathrm{Al}\end{array}$} \\
\hline & $* *$ & & & & $* *$ & \\
\hline & 2.785 & & 2.768 & 2.770 & 6.347 & \\
\hline & 2.778 & & 2.780 & 2.774 & 6.378 & \\
\hline & 2.773 & & 2.780 & 2.770 & 6.363 & \\
\hline & 2.784 & & 2.782 & & & \\
\hline & 2.794 & & 2.797 & & & \\
\hline & 2.788 & & 2.797 & & & \\
\hline & 2.797 & & & & & \\
\hline & 2.772 & & & & & \\
\hline & 2.785 & & & & & \\
\hline Mean velocity & & 2.784 & & 2.771 & 6.363 & \\
\hline Range (\%) & & +0.467 & & +0.108 & +0.236 & \\
\hline & & -0.575 & & -0.001 & -0.251 & \\
\hline Postcruise recalculated $K^{\prime}$ & & 0.9860 & & 0.9906 & 0.9893 & \\
\hline$K p$ & & & 0.9886 & & & $=$ Mean $K^{\prime}$ \\
\hline Shipboard mean $K$ & & & 0.9880 & & & \\
\hline
\end{tabular}

Note: The best precision occurs when using the full range of the "cm-delay" dial: *** = best use of the $\mathrm{cm}$-delay dial: 0 to 10.0 range; $* *=$ fair use of the cm-delay dial: 0 to 6.0 range; $*=$ poor use of the cm-delay dial: 0 to 3.0 range. (Mean velocity) $K^{\prime}=$ true velocity for $\mathrm{Al}=6.295$ $\mathrm{km} / \mathrm{sec}$ and for Lucite $=2.745 \mathrm{~km} / \mathrm{sec}$.

TABLE 11

Weighing of the 200,500 , and $800 \mathrm{mg}$ Standard Weights with the Cahn

Gram Electro Balance on

Glomar Challenger While at Sea

\begin{tabular}{ccc}
\multicolumn{3}{c}{ Weight Standards $(\mathrm{mg})$} \\
\hline 200 & 500 & 800 \\
& & \\
199.0 & 497.7 & 795.7 \\
200.2 & 500.9 & 800.3 \\
200.1 & 501.0 & 799.4 \\
\hline
\end{tabular}

cuss enough theory to establish the problem and its solution and will be basically from Evans (1965) and Evans and Cotterell (1970).

If the gamma-ray energy is within certain limits ( 0.2 to $1.02 \mathrm{MeV}$ ), the gamma rays passing through most geological material will be attenuated primarily by Compton scattering. The following equation is the basis for attenuation of a parallel, "monoenergetic," gammaray beam in an ideal slab absorber (Evans, 1965):

$$
\begin{gathered}
I=I_{O} \epsilon-\mu d r \\
\rho_{B}=\left(\frac{1}{\mu d}\right) \ln \left(I_{O} / I\right)
\end{gathered}
$$

where,

$I$ is the intensity of the gamma-ray beam which penetrates the absorber with no loss in energy, $I_{O}$ is source intensity.
$\rho_{\mathrm{B}}$ is the bulk density in $\mathrm{g} / \mathrm{cc}$.

$\mu$ is the Compton mass attenuation coefficient in $\mathrm{cm}^{2} / \mathrm{g}$, and

$d$ is the thickness of diameter of the sample in $\mathrm{cm}$.

The basic problem in using Equation 15 to determine density, particularly wet-bulk density, is that all minerals do not have the same attenuation coefficient. Water, for example, has an attenuation coefficient which is $10 \%$ greater than that of quartz. According to Evans (1965) if the quartz Compton mass attenuation coefficient is theoretically set equivalent to $0.100 \mathrm{~cm}^{2} / \mathrm{g}$, then water is theoretically $0.110 \mathrm{~cm}^{2} / \mathrm{g}$ (for a particular $\mathrm{MeV}$ energy of ${ }^{13} \mathrm{Ba}$ as a gamma-ray source). The attenuation coefficient of quartz is approximately correct for most minerals, but in some sediments it may be necessary to make corrections for minerals whose attenuation coefficients differ significantly from that of quartz (discussed in Boyce, 1973, and Brier et al., 1969). At present we will only discuss the correction for the differences in the quartz and water attenuation coefficients.

Evans (1965) suggests that the most convenient approach in using Equation 15 is to consider $\mu$ to be that of quartz as a reference and use "corrected" densities for any mineral components which do not have attenuation coefficients near $( \pm 3 \%)$ that of quartz. If a mineral has an attenuation coefficient different from that of quartz, then its "corrected" density would be the density obtained using Equation 15 with an attenuation coefficient of quartz instead of the actual attenuation coefficient of the "anomalous" mineral. For example, the "corrected" density of water is $1.10 \mathrm{~g} / \mathrm{cc}$ (true density is $1.00 \mathrm{~g} / \mathrm{cc}$ ) which would be obtained if Equation 15 was used with a quartz attenuation coefficient. Harms and Choquette (1965) and Evans and Cotterell (1970) con- 
tain tables listing some minerals with their true density and "corrected" density.

If one assumes that a sediment sample is made up of quartz with a theoretical $0.100 \mathrm{~cm}^{2} / \mathrm{g}$ attenuation coefficient, and sea water with a theoretical attenuation of $0.110 \mathrm{~cm}^{2} / \mathrm{g}$, then by using Equation 15 with a theoretical $0.100 \mathrm{~cm}^{2} / \mathrm{g}$ attenuation coefficient, the sediment would appear to be made up of grains with a density of $2.65 \mathrm{~g} / \mathrm{cc}$ and a fluid with a density of $1.128 \mathrm{~g} / \mathrm{cc}$ ("corrected" density of sea water). Now porosity may be determined from a "corrected" wet-bulk density from Equation 15 if the "corrected" grain density and "corrected" fluid density are known (Evans, 1965; Evans and Cotterell, 1970) according to the following equation:

$$
\phi=\frac{\rho_{g c}-\rho_{b c}}{\rho_{g c}-\rho_{f c}}
$$

where,

$\phi=$ porosity: (volume pore space/volume wetsaturated sediment)

$\rho_{g c}=$ grain density in g/cc: "corrected" grain density if minerals have an attenuation coefficient differing from that of quartz.

$\rho_{f c}=$ fluid density in g/cc: "corrected" fluid density if the fluid has an attenuation coefficient differing from that of quartz.

$\rho_{b c}=$ wet-bulk density in $\mathrm{g} / \mathrm{cc}$ from Equation 15: This is a "corrected" wet-bulk density if the minerals or fluids do not have an attenuation coefficient of quartz.

Also the following equation is true for wet-saturated sediment:

$$
\phi=\frac{\rho_{g}-\rho_{b}}{\rho_{g}-\rho_{f}}
$$

where,

$$
\begin{aligned}
& \rho g=\text { true grain density in } \mathrm{g} / \mathrm{cc} \\
& \rho f=\text { true fluid density in } \mathrm{g} / \mathrm{cc} \\
& \rho b=\text { true wet-bulk density in } \mathrm{g} / \mathrm{cc}
\end{aligned}
$$

Thus, the following relationship can be established which has not been precisely stated by previous investigators (Figure 1):

$$
\frac{\rho_{g}-\rho_{b}}{\rho_{g}-\rho_{f}}=\phi=\frac{\rho_{g c}-\rho_{b c}}{\rho_{g c}-\rho_{f c}}
$$

Therefore, true wet-bulk density may be determined by measuring a "corrected" wet-bulk density if, in addition, the investigator knows the grain density, fluid density, "corrected" grain density, and "corrected" fluid density of the sample:

$$
\rho_{b}=\rho_{g}-\left[\frac{\left(\rho_{g c}-\rho_{b c}\right)\left(\rho_{g}-\rho_{f}\right)}{\left(\rho_{g c}-\rho_{f c}\right)}\right]
$$

Since:

$$
1-\phi=\frac{\rho_{b}-\rho_{f}}{\rho_{g}-\rho_{f}}=\frac{\rho_{b c}-\rho_{f c}}{\rho_{g c}-\rho_{f c}}
$$

Therefore, the following is also true:

$$
\rho_{b}=\left[\frac{\left(\rho_{b c}-\rho_{f c}\right)\left(\rho_{g}-\rho_{f}\right)}{\left(\rho_{g c}-\rho_{f c}\right)}\right]+\rho_{f}
$$

The true wet-bulk density from Equations 19 or 21, and the porosity from Equation 18, will be accurate if correct values from grain density and "corrected" density are chosen.

For DSDP data the GRAPE porosity is calculated for publication using $\rho b$ from Equation 21 and substituting $\rho_{b}$ into Equation 17.

\section{Error of Theoretical Assumptions}

Although the porosity in Equation 18 has a tremendous error if grain densities are not accurately known, the wet-bulk density determination (Equation 19 or 21) is only slightly affected. In routine investigations of marine sediments with varying lithologies, the only parameters which an investigator would not normally know accurately are the grain densities and corresponding "corrected" grain densities. The fluid densities and "corrected" fluid densities should be known (or can be easily measured), and the "corrected" wet-bulk density is measured with the gamma-ray device. For example, if one did not know what the proper grain densities were, and assumed $2.6 \mathrm{~g} / \mathrm{cc}$ as the grain density (assuming "corrected" density is the same as the true density, which is the same as assuming the grains have an attenuation coefficient of quartz) then the following systematic errors in wet-bulk density would ensue. The greatest systematic error in the wet-bulk density determination is about $-2 \%$ which occurs when the true grain density is $2.0 \mathrm{~g} / \mathrm{cc}$ and the rock has zero percent porosity. If the rock has zero porosity and the true grain density is 2.3 or $3.0 \mathrm{~g} / \mathrm{cc}$, then the errors in wet-bulk density are $-0.8 \%$ and $+0.8 \%$, respectively, These errors, however, are inversely proportional to porosity as there is no error resulting from improper grain density at $100 \%$ porosity. Therefore at $50 \%$ true porosity these errors decrease by half, and at $80 \%$ true porosity these errors decrease by $80 \%$, and at $100 \%$ porosity these errors decrease by $100 \%$.

Porosity, however, may have an extremely large systematic error when a $2.6 \mathrm{~g} / \mathrm{cc}$ grain density is assumed. For example, if the true grain density is $2.0 \mathrm{~g} / \mathrm{cc}$ then when the true wet-bulk density is also $2.0 \mathrm{~g} / \mathrm{cc}$, the porosity should be zero instead of $38 \%$ determined by assuming a $2.6 \mathrm{~g} / \mathrm{cc}$ grain density. When the true grain density is $2.6 \mathrm{~g} / \mathrm{cc}$ there is no error. When the true grain density is $3.0 \mathrm{~g} / \mathrm{cc}$ with a true wet-bulk density of 3.0 $\mathrm{g} / \mathrm{cc}$ then the true porosity is $0 \%$ and not $-26 \%$ erroneously determined by assuming a grain density of 2.6 $\mathrm{g} / \mathrm{cc}$. Of course these errors are inversely proportional to true porosity. If the true porosity is $50 \%$ then these 
R. E. BOYCE

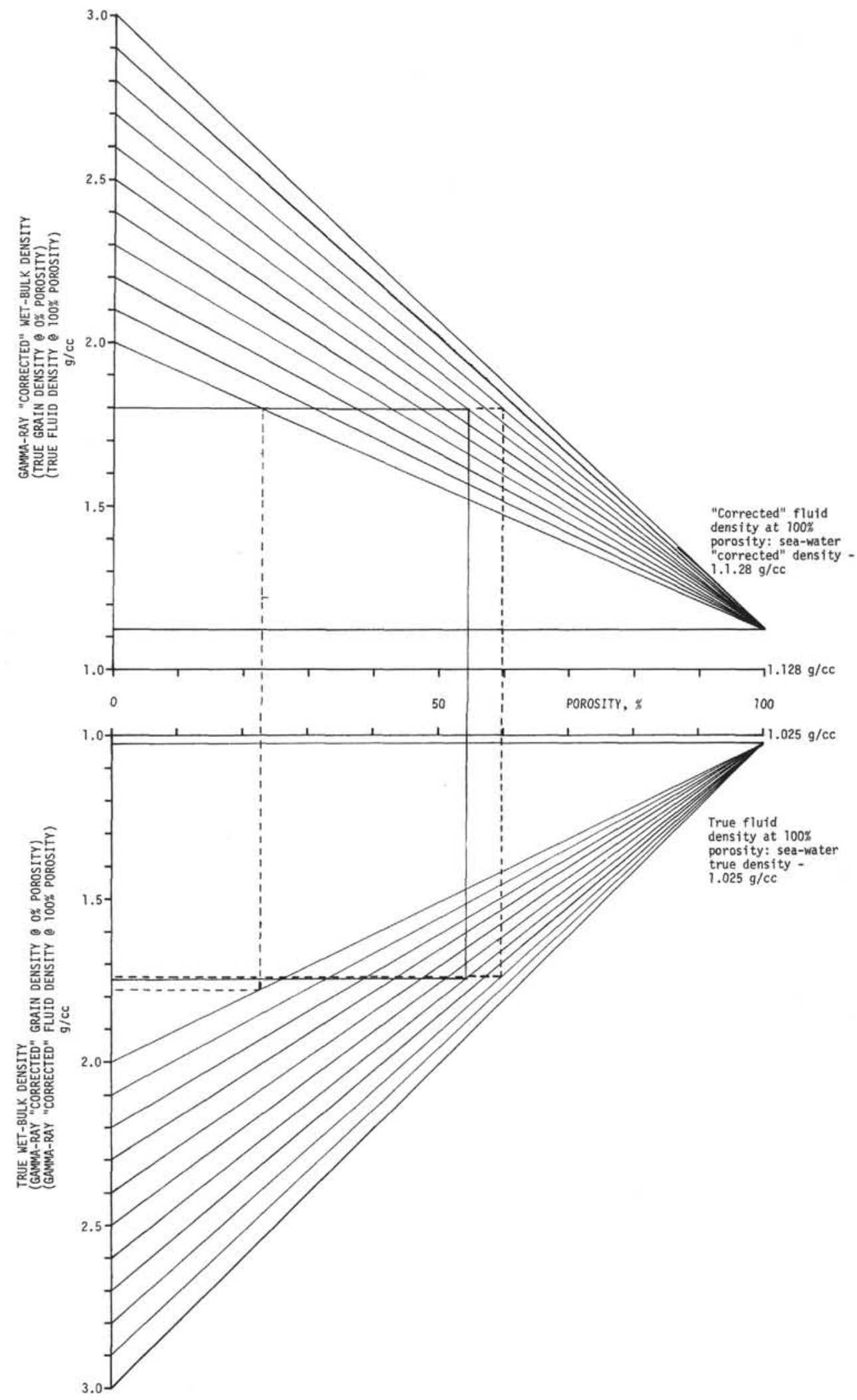

Figure 1. The graphical solutions to Equations 16 through 21. If a gamma ray "corrected" wet-bulk density of 1.8 g/cc is obtained it can be fully converted to true wet-bulk density by the following graphical solution. The value of $1.8 \mathrm{~g} / \mathrm{cc}$ is found on the GAMMA RAY "CORRECTED" WET-BULK DENSITY scale. It is then extrapolated horizontally until it intersects a slanted line connecting the "corrected" grain density(@0\% porosity) and the "corrected" fluid density(@100\% porosity). By vertical extrapolation from this intersection to the POROSITY scale (will be true porosity if "corrected" densities are accurate) and through to the lower graph until intersecting with the slanted line connecting the true fluid' density (@100\% porosity) to the true grain density (@0\% porosity). From this intersection move horizontally to 
intersect with the TRUE WET-BULK DENSITY scale which will be the true wet-bulk density. (This assumes all mineral grains have the same attenuation coefficient and that the proper "corrected" grain and fluid densities, and proper true grain and fluid densities have been selected.) The dotted lines show the same $1.8 \mathrm{~g} / \mathrm{cc}$ corrected wet-bulk density using other grain densities of 2.0 and $2.8 \mathrm{~g} / \mathrm{cc}$.

errors are decreased by $50 \%$. When true porosity if $100 \%$ the error is reduced by $100 \%$.

\section{Error as a Result of}

\section{Random Gamma-Ray Emissions}

The GRAPE has been modified from its original equipment as described by Evans (1965), in that we are now recording in the continuous mode, in addition to the analog records, digital magnetic tape records with a 2 -second counting period. Error, in terms of wet-bulk density, resulting from the random gamma-ray emmissions from a ${ }^{133} \mathrm{Ba}$ source has a range of $\pm 6 \%$ with a typical standard deviation of $1.8 \%$. Standard deviation (for normal distribution, Alder and Roessler, 1972, p. 40) ranged from 1.27 to $2.00 \%$ with 10 sets of 602 second counts. This error depends on the density of the sample and how many counts per density measurement. Investigators desiring high precision should count for longer periods (Brier et al., 1969). Tables 12 and 13 contain raw gamma counts and corresponding densities with their means, standard deviations, and ranges. Figures 2 through 7 are frequency histograms of the raw gamma counts and corresponding densities.

When using the GRAPE analog (continuous mode) data, if a core is homogeneous for about $20 \mathrm{~cm}$, this would be approximately equivalent to 602 -second counts and the average density determined would be statistically similar to that of the 60 variates in Tables 12 and 13, and Figures 2 through 7. By averaging different numbers of 2 -second counts, one can determine the probable error in averaging data over differing lengths of cores.

\section{DSDP GRAPE Application: Static Mode}

The GRAPE can be operated in a continuous mode and a static mode. The static mode will be discussed below. The static mode allows individual samples to be run and counted for a 2 -minute period with a precision of \pm 1 or $2 \%$. These samples are labeled as "GRAPE Special 2-Minute" count wet-bulk density.

The ${ }^{13} \mathrm{Ba}$ is not actually a single energy source of gamma rays. It actually gives gamma rays at a range of energies, but the 0.3 and $0.36 \mathrm{MeV}$ energy levels are selected by adjusting the lower threshold voltage level of the $\mathrm{MeV}$ window of the GRAPE System, but this cannot be finely controlled (see Appendices $\mathrm{C}$ and E). Problems arise here because the mass attenuation coefficient varies inversely with the $\mathrm{MeV}$ energy of the gamma rays (see fig. 4 of Evans, 1965). Therefore we cannot calculate density from the $I_{O}, I$, and $d$ measurements without using standards to determine the empirical apparent mass attenuation coefficient of quartz. This coefficient will not exactly be the theoretical $0.100 \mathrm{~cm}^{2} / \mathrm{g}$ discussed earlier but will vary about $10 \%$ depending on the DSDP GRAPE MeV energy "window" adjustment.

Therefore, for "GRAPE Special 2-Minute" count density data, it is first necessary to calculate the apparent quartz mass attenuation coefficient. Apparent
TABLE 12

Gamma Counts Per 2-sec Periods for Air, Empty Liner, Distilled Water $(6.61 \mathrm{~cm})$ in Liner, Aluminum $(6.61 \mathrm{~cm})$ in Liner ${ }^{\mathrm{a}}$

\begin{tabular}{|c|c|c|c|c|c|c|c|}
\hline \multicolumn{2}{|c|}{ Air } & \multicolumn{2}{|c|}{ Liner } & \multicolumn{2}{|c|}{ Water } & \multicolumn{2}{|c|}{ Aluminum } \\
\hline 9617 & 9738 & 9076 & 9116 & 4291 & 4334 & 1571 & 1578 \\
\hline 9674 & 9496 & 9081 & 9063 & 4240 & 4215 & 1627 & 1550 \\
\hline 9735 & 9788 & 8069 & 9018 & 4254 & 4305 & 1549 & 1466 \\
\hline 9787 & 9786 & 9105 & 9063 & 4295 & 4082 & 1569 & 1544 \\
\hline 9675 & 9722 & 8979 & 8931 & 4308 & 4224 & 1527 & 1486 \\
\hline 9683 & 9723 & 9179 & 8885 & 4264 & 4304 & 1567 & 1472 \\
\hline 9755 & 9773 & 9041 & 9082 & 4336 & 4198 & 1489 & 1476 \\
\hline 9663 & 9606 & 9018 & 9005 & 4240 & 4340 & 1564 & 1479 \\
\hline 9636 & 9741 & 8992 & 9134 & 4259 & 4351 & 1543 & 1503 \\
\hline 9473 & 9643 & 9099 & 9059 & 4291 & 4375 & 1512 & 1504 \\
\hline 9664 & 9627 & 9000 & 9034 & 4401 & 4202 & 1565 & 1541 \\
\hline 9625 & 9620 & 9077 & 9217 & 4275 & 4298 & 1507 & 1516 \\
\hline 9722 & 9693 & 9081 & 8869 & 4272 & 4299 & 1575 & 1509 \\
\hline 9772 & 9564 & 9008 & 9039 & 4344 & 4116 & 1527 & 1545 \\
\hline 9772 & 9692 & 9243 & 8897 & 4359 & 4224 & 1574 & 1502 \\
\hline 9765 & 9735 & 9026 & 9249 & 4295 & 4288 & 1550 & 1544 \\
\hline 9575 & 9602 & 9118 & 9204 & 4198 & 4207 & 1621 & 1562 \\
\hline 9778 & 9679 & 9088 & 9201 & 4269 & 4316 & 1433 & 1573 \\
\hline 9697 & 9702 & 9099 & 9103 & 4302 & 4314 & 1576 & 1512 \\
\hline 9724 & 9498 & 9073 & 9133 & 4347 & 4334 & 1541 & 1593 \\
\hline 9494 & 9639 & 9086 & 9197 & 4293 & 4282 & 1530 & 1619 \\
\hline 9723 & 9663 & 8843 & 9085 & 4331 & 4284 & 1587 & 1471 \\
\hline 9890 & 9455 & 9063 & 9022 & 4317 & 4199 & 1563 & 1467 \\
\hline 9810 & 9654 & 9075 & 9234 & 4193 & 4222 & 1565 & 1507 \\
\hline 9746 & 9529 & 9124 & 8906 & 4289 & 4246 & 1536 & 1529 \\
\hline 9383 & 9651 & 9150 & 9063 & 4173 & 4160 & 1503 & 1587 \\
\hline 9654 & 9708 & 9061 & 9109 & 4252 & 4314 & 1566 & 1514 \\
\hline 9863 & 9655 & 8976 & 9125 & 4273 & 4343 & 1623 & 1508 \\
\hline 9654 & & 9008 & 9029 & 4250 & 4323 & 1648 & 1495 \\
\hline 9703 & & 9042 & 8953 & 4434 & 4237 & 1560 & \\
\hline
\end{tabular}

\begin{tabular}{llll}
58 variates & 60 variates & 60 variates & 59 variates \\
Mean $=$ & Mean $=$ & Mean $=$ & Mean $=$ \\
9674.0 & 9063.4 & 4274.6 & 1539.3 \\
Standard & Standard & Standard & Standard \\
Deviation & Deviation & Deviation & Deviation \\
$=99.8$ & $=90.6$ & $=64.6$ & $=45.3$ \\
$=1.03 \%$ & $=1.00 \%$ & $=1.51 \%$ & $=2.94 \%$ \\
Range & Range & Range & Range \\
$=+2.23 \%$ & $=+2.05 \%$ & $=+3.73 \%$ & $=+7.06 \%$ \\
$-3.00 \%$ & $-2.43 \%$ & $-4.50 \%$ & $-7.10 \%$ \\
\hline
\end{tabular}

a Data from Leg 24.

when used here will signify any attenuation coefficient characteristic of the adjustments of the DSDP GRAPE equipment. In other words, the attenuation coefficient needed to derive true densities from raw $I, I_{O}$, and thickness measurements. For example, from the quartz standard:

$$
\text { apparent quartz } \mu=\frac{\ln \left(I_{O} / I\right)}{(2.65 \mathrm{~g} / \mathrm{cc}) d}
$$

This mass attenuation coefficient has an empirical derivation and is characteristic of the energy window of the ${ }^{133} \mathrm{Ba}$ gamma source. 
TABLE 13

Gamma-Ray Density for Distilled Water and Aluminum in Liners Counted for 2-sec. Periods ${ }^{\mathrm{a}}$

\begin{tabular}{|c|c|c|c|}
\hline \multicolumn{2}{|c|}{$\begin{array}{l}\text { Distilled Water } \\
\text { in Liner }\end{array}$} & \multicolumn{2}{|c|}{$\begin{array}{l}\text { Aluminum } \\
\text { in Liner }\end{array}$} \\
\hline 1.003 & 0.959 & 2.522 & 2.593 \\
\hline 1.019 & 0.990 & 2.595 & 2.676 \\
\hline 1.015 & 1.027 & 2.576 & 2.600 \\
\hline 1.001 & 0.999 & 2.616 & 2.656 \\
\hline 0.998 & 1.070 & 2.578 & 2.670 \\
\hline 1.011 & 1.024 & 2.653 & 2.666 \\
\hline 0.989 & 0.993 & 2.581 & 2.662 \\
\hline 1.019 & 1.020 & 2.601 & 2.638 \\
\hline 1.013 & 0.999 & 2.630 & 2.639 \\
\hline 1.003 & 1.032 & 2.580 & 2.602 \\
\hline 0.969 & 0.988 & 2.635 & 2.626 \\
\hline 1.008 & 0.984 & 2.570 & 2.633 \\
\hline 1.009 & 0.977 & 2.616 & 2.599 \\
\hline 0.982 & 1.031 & 2.571 & 2.640 \\
\hline 0.987 & 1.001 & 2.593 & 2.600 \\
\hline 1.002 & 1.000 & 2.528 & 2.582 \\
\hline 1.032 & 1.059 & 2.709 & 2.572 \\
\hline 1.010 & 1.024 & 2.569 & 2.630 \\
\hline 1.000 & 1.004 & 2.602 & 2.554 \\
\hline 0.988 & 1.029 & 2.613 & 2.530 \\
\hline 1.017 & 0.995 & 2.559 & 2.671 \\
\hline 1.002 & 0.996 & 2.582 & 2.675 \\
\hline 0.991 & 0.996 & 2.580 & 2.635 \\
\hline 0.995 & 1.006 & 2.607 & 2.614 \\
\hline 1.034 & 1.005 & 2.639 & 2.559 \\
\hline 1.004 & 1.025 & 2.579 & 2.628 \\
\hline 1.040 & 1.017 & 2.526 & 2.634 \\
\hline 1.015 & 1.044 & 2.503 & 2.647 \\
\hline 1.009 & 0.996 & 2.584 & 2.574 \\
\hline 1.016 & 1.032 & 2.568 & \\
\hline \multicolumn{2}{|c|}{60 variates } & \multicolumn{2}{|c|}{59 variates } \\
\hline \multicolumn{2}{|c|}{$\begin{array}{c}\text { Mean }= \\
1.008\end{array}$} & \multicolumn{2}{|c|}{$\begin{array}{l}\text { Mean }= \\
2.605\end{array}$} \\
\hline \multirow{2}{*}{\multicolumn{2}{|c|}{$\begin{array}{l}\text { Standard } \\
\text { Deviation } \\
=0.017 \\
1.72 \%\end{array}$}} & \multirow{2}{*}{\multicolumn{2}{|c|}{$\begin{array}{l}\text { Standard } \\
\text { Deviation } \\
=0.042 \\
1.63 \%\end{array}$}} \\
\hline & & & \\
\hline \multicolumn{2}{|c|}{$\begin{array}{l}\text { Range } \\
\begin{aligned}= & +6.14 \% \\
& -4.86 \%\end{aligned}\end{array}$} & \multicolumn{2}{|c|}{$\begin{array}{l}\text { Range } \\
=+4.32 \% \\
\quad-3.92 \%\end{array}$} \\
\hline
\end{tabular}

${ }^{\text {aD }}$ ata from Leg 24.

bWater density was calculated by $\rho=\frac{\ln \left(I_{O} / I\right)}{\mu d}$ where $I_{o}$ is 9063.4 , $\mu$ is an empirical value, for our $\mathrm{MeV}$ adjustment on our gamma source, of $0.113 \mathrm{~cm}^{2} / \mathrm{g}, d$ is $6.61 \mathrm{~cm}$.

c"Corrected" aluminum density was calculated by $\rho=\frac{\operatorname{In}\left(I_{O} / I\right)}{\mu d}$ where $I_{O}$ is $9063.4, \mu$ is an empirical value for quartz for quartz for our $\mathrm{MeV}$ adjustment on our gamma source, of $0.103 \mathrm{~cm}^{2} / \mathrm{g}, d$ is $6.61 \mathrm{~cm}$.

An apparent quartz mass attenuation coefficient can also be calculated using aluminum standards (Alcoa $1100-\mathrm{F}$, true density $=2.71 \mathrm{~g} / \mathrm{cc}$ ), assuming a $2.60 \mathrm{~g} / \mathrm{cc}$ corrected aluminum density (Evans, 1965; Schlumberger, 1972) and calculating as follows:

$$
\text { apparent quartz } \mu_{\mathrm{A} 1}=\frac{\ln \left(I_{O} / D\right)}{d(2.60 \mathrm{~g} / \mathrm{cc})}
$$

In order to calculate the Leg 33 GRAPE Special 2Minute Count density data with the proper apparent quartz mass attenuation coefficient, all of Leg 33 presite standards (aluminum "telescope" which has different diameters) and all routine aluminum standards (6.61 and $2.54 \mathrm{~cm}$ diameters), which are normally run between each core, had their apparent mass attenuation coefficients calculated. The data from varying thicknesses of aluminum indicate that the density or apparent quartz attenuation coefficient has a slight $(3 \%)$ dependence on the diameter of the aluminum sample for all standards. The results of these data are shown in Figure 8. Since Leg 33 only had five good aluminum "telescope" runs, there was not enough data statistically to determine if the relationship is curved or a straight line. However G. Bode (personal communication, 1974) specially measured the coefficients of the aluminum "telescope" on Leg 37 and his data indicated an approximate linear relationship (see Figure 8). Since many routine standards were averaged for the entire Leg 33, they are statistically weighed as correct, although only end members of the data are provided. For Leg 33 data and for practical purposes, a linear interpolation between these two coefficient values, based on sample thickness, was used to obtain the proper coefficient to calculate the wet-bulk density of the GRAPE Special 2-Minute Count rock sample. This may not be exactly the proper value, but the error will be about $0.5 \%$ or less, which is good when considering the total error of $\pm 2 \%$ of the density value caused by the gamma-ray emission statistical variation, and if necessary this linear interpolation can easily be corrected after publication.

For the Leg 33 data the "corrected" wet-bulk density of the GRAPE Special 2-Minute Count rock sample was calculated as follows:

$$
\rho_{b c}=\text { "corrected" density }=\frac{\ln \left(I_{O} / I\right)}{d \mu_{a}}
$$

where $\mu_{a}$ is the apparent quartz mass attenuation coefficients, which were determined using a straight line (dashed line in Figure 8) interpolation, based on sample thickness, between the routine $2.54-\mathrm{cm}$ aluminum averaged apparent quartz mass attenuation coefficient $\left(0.10915 \mathrm{~cm}^{2} / \mathrm{g}\right)$ and the $6.61 \mathrm{~cm}$ aluminum averaged apparent quartz mass attenuation coefficient $(0.10584$ $\mathrm{cm}^{2} / \mathrm{g}$ ). However, these "corrected" wet-bulk density values will be in error because the GRAPE equation does not allow for a difference between theoretical mass attenuation coefficients of water $\left(0.1099 \mathrm{~cm}^{2} / \mathrm{g}\right)$ and that of the mineral grains (about $0.1000 \mathrm{~cm}^{2} / \mathrm{g}$ ). This error can be overcome by using Equation 21 (as discussed earlier) to solve for true wet-bulk density.

For the Leg 33 data Equation 21 used the following parameters: $\rho g$ and $\rho g c$ were 2.70 for all sedimentary rocks except chert whose values were $2.65 \mathrm{~g} / \mathrm{cc}$. Basalt values were $2.86 \mathrm{~g} / \mathrm{cc}$. The only variation from this is the celestite sample from Site 315 , Core 8 , where only the "corrected" wet-bulk density was reported. $\rho_{f}$ was 1.025 $\mathrm{g} / \mathrm{cc}$ and $\rho_{f c}$ was $1.128 \mathrm{~g} / \mathrm{cc}$. 


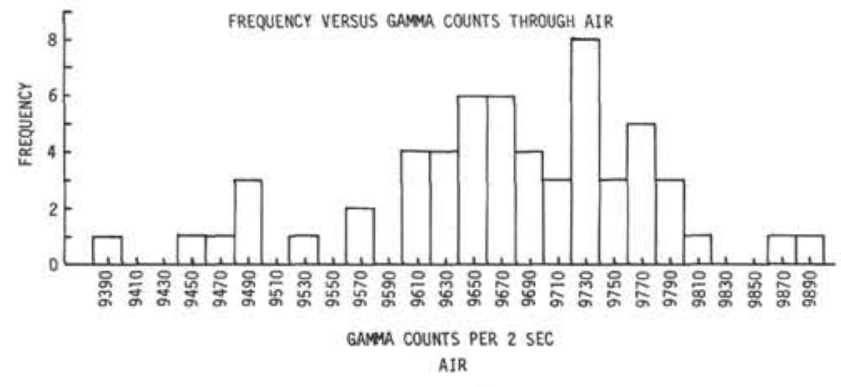

Figure 2. Frequency histogram for gamma counts through air, which were measured during a 2-second counting period.

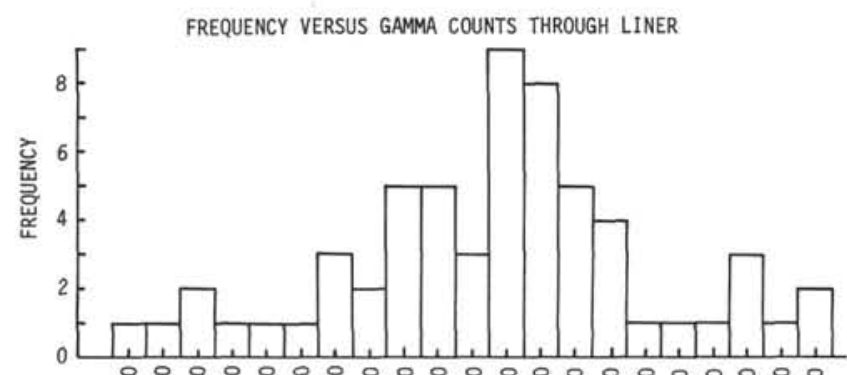

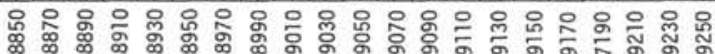

GAMMA COUNTS PER 2 SEC

LINER

Figure 3. Frequency histogram for gamma counts through an empty $6.61 \mathrm{~cm}$ internal diameter core liner. A 2-second counting period was used.

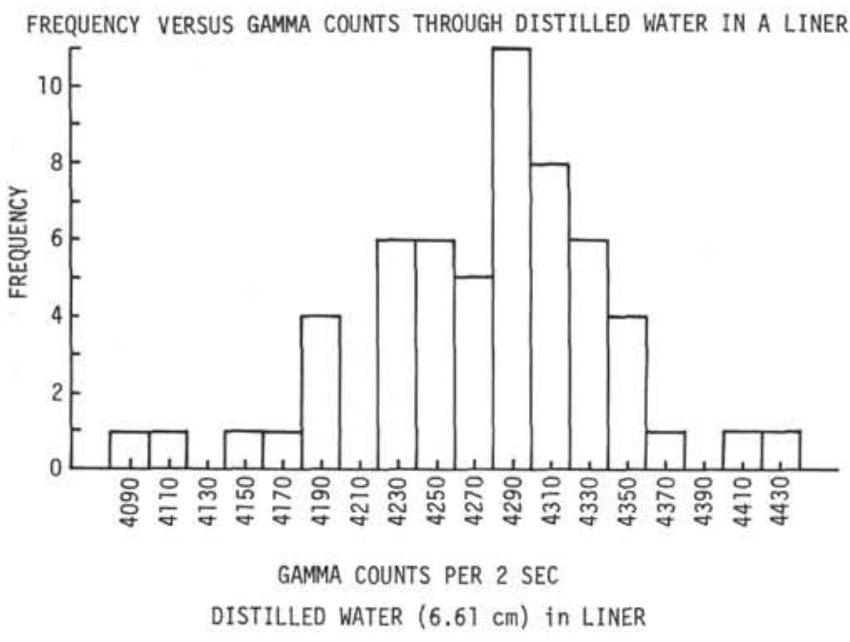

Figure 4. Frequency histogram for gamma counts through distilled water in a $6.61 \mathrm{~cm}$ internal diameter core liner. A 2-second counting period was used.

\section{Apparent Quartz Mass Attenuation Coefficient Discussion}

Other legs should study the aluminum standards run on their cruise in order to reduce their cylinder technique or the rock sample GRAPE Special 2-Minute Count density data correctly. Other legs should not use the Leg 33 attenuation coefficient values in their

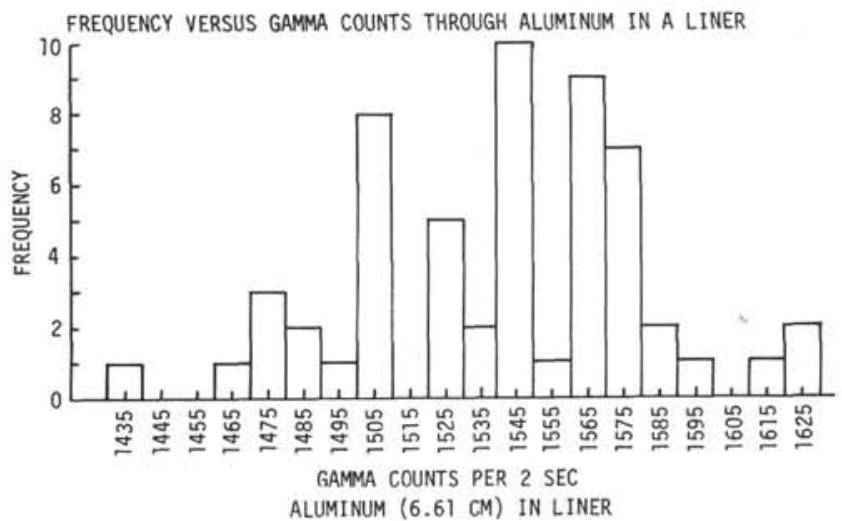

Figure 5. Frequency histogram for gamma counts through aluminum $(6.61 \mathrm{~cm})$ in a plastic liner. A 2-second counting period was used.

calculations as the coefficient values may be different on other legs, depending on the adjustment of the $\mathrm{MeV}$ energy interval on the GRAPE instrument.

At the present time the author has not decided whether this thickness-coefficient variation is a true function in the nuclear technique or an artifact generated by the DSDP GRAPE instrument; thus, these coefficient variations for different sample thicknesses are subject to further study. ${ }^{2}$ However, because the analog data are calibrated with standards $6.61 \mathrm{~cm}$ in diameter and samples are predominantly $6.61 \mathrm{~cm}$ in diameter, the apparent mass attenuation coefficient will be considered, as a matter of reference, to be that of the $6.61-\mathrm{cm}$ diameter aluminum standard. Therefore where DSDP legs have used smaller diameter $(2.54 \mathrm{~cm})$ aluminum standards to substitute for the $6.61-\mathrm{cm}$ diameter water standard, then the density values assigned to this small standard in the routine analog program should be adjusted so that each $6.61-\mathrm{cm}$ and $2.54-\mathrm{cm}$ standard will have the same apparent mass attenuation coefficient, which by Leg 33 definition will be that of the larger standard. Therefore the $1.00 \mathrm{~g} / \mathrm{cc}$ density assigned to the small aluminum standard on previous legs will be changed for Leg 33 data to 1.03 $\mathrm{g} / \mathrm{cc}$.

The relationships of all the standards, $6.61-\mathrm{cm}$ aluminum and distilled water ${ }^{3}$ and the $2.54-\mathrm{cm}$ aluminum are empirically calibrated before and after every site, when these standards are run as a group through the GRAPE analog system. The multidiameter aluminum "telescope" is run by itself as one of the presite and postsite standards. This procedure has been in practice since the introduction of the magnetic tape data from the GRAPE, therefore any deviation in DSDP equipment or standards can be studied statistically. They must be studied by statistical averages because the differences of $3 \%$ or less can be blurred, in only one or two runs of the standards, by the $\pm 11 \%$ precision of the final analog density data.

\footnotetext{
${ }^{2}$ This problem appears to have been the result of an improver $\mathrm{MeV}$ "window" adjustment, which has been readjusted on Leg 39.

${ }^{3} \mathrm{~A}$ problem with the water standard is that the water is inside a normal core liner, and one is never certain of the exact internal diameter.
} 


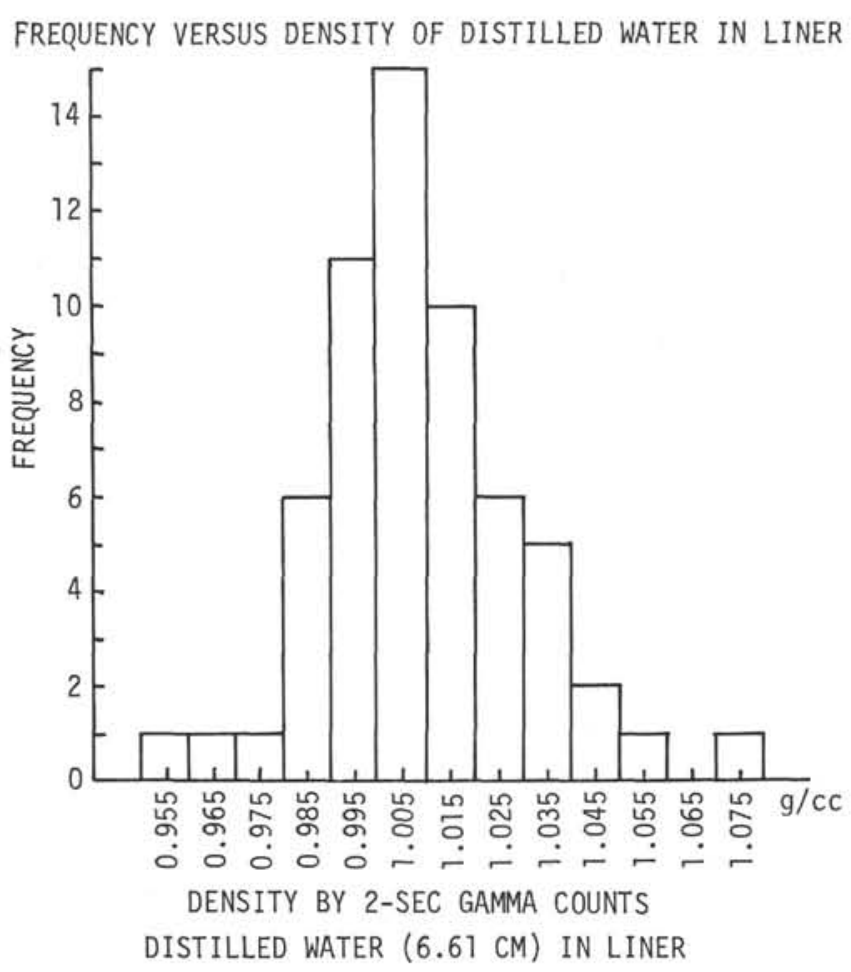

Figure 6. Frequency histogram of gamma ray density determinations of distilled water $(6.61 \mathrm{~cm})$ in a liner. Each variate was counted for a 2-second period and calculated with the same average $I_{O}$ (average gamma count through an empty liner).

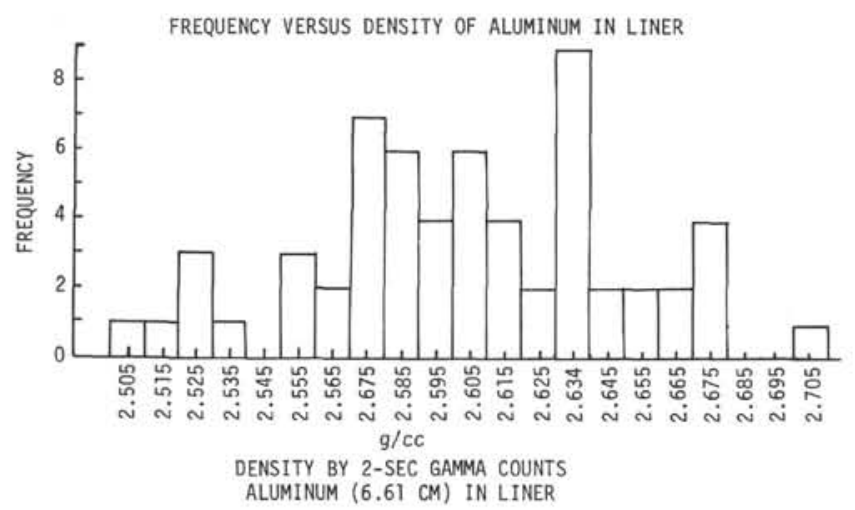

Figure 7. Frequency histogram of gamma ray density determinations of aluminum $(6.61 \mathrm{~cm})$ in a liner. Each variate was counted for a 2-second period and was calculated with the same average $I_{O}$ (average gamma count through an empty liner) The value of $2.6 \mathrm{~g} / \mathrm{cc}$ is a "corrected" density relative to a quartz attenuation coefficient, as the true density of the aluminum is $2.71 \mathrm{~g} / \mathrm{cc}$.

\section{GRAPE Analog Data and \\ Magnetic Tape Data: \\ Continuous Mode}

The GRAPE Analog equipment also operates in a continuous mode, where it calculates and makes an analog plot of the "corrected" density, which is continuously measured along the length of the core. The
Diameter of Aluminum Versus Apparent Quartz Mass Attenuation Coefficient

- Special averages from Bode, Leg 37

- Leg 33 individual presite standards

Leg 33 average of presite standards

$\triangle \quad$ Average of a $11 \mathrm{Leg} 33$ routine standards run before each core

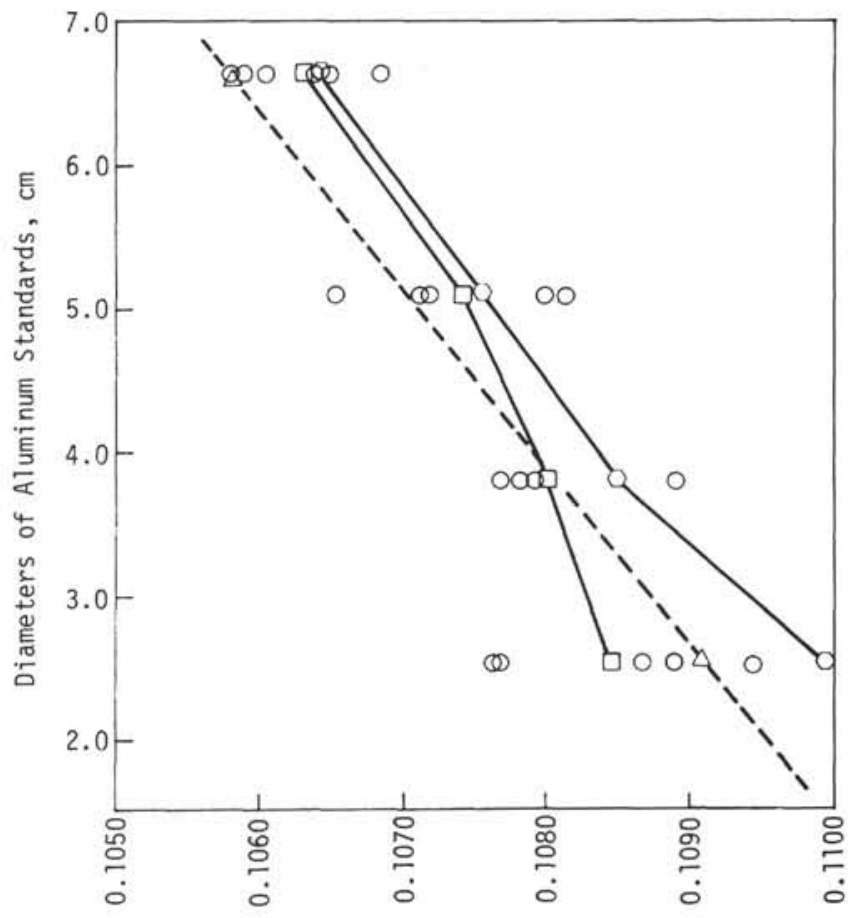

Apparent Quartz Mass Attenuation Coefficient, $\mathrm{cm}^{2} / \mathrm{g}$

$$
\mu=\frac{\ln (\mathrm{Io} / \mathrm{I})}{\mathrm{d} 2.60 \mathrm{~g} / \mathrm{cc}}
$$

Figure 8. The apparent quartz mass attenuation coefficient varies about $3 \%$ depending on the diameter of the aluminum standard. Leg 33, GRAPE Special 2-Minute Count density data were calculated with apparent quartz mass attenuation coefficients, which were determined using a straight line (dashed line) interpolation, based on sample thickness, between the routine $2.54 \mathrm{~cm}$ aluminum averaged apparent quartz mass attenuation coefficient $\left(0.10915 \mathrm{~cm}^{2} / \mathrm{g}\right)$ and the $6.61 \mathrm{~cm}$ aluminum averaged apparent quartz mass attenuation coefficient 10.10915 $\mathrm{cm}^{2} / \mathrm{g}$ ) and the $6.61 \mathrm{~cm}$ aluminum averaged apparent quartz mass attenuation coefficient $\left(0.10584 \mathrm{~cm}^{2} / \mathrm{g}\right)$.

gamma beam of the GRAPE system is about the size of a pencil across the diameter of the core, and the cores move lengthwise at a speed of $3.17 \mathrm{~mm}$ every 2 seconds.

The new magnetic tape system measures the total gamma count for a 2 -second counting period which is recorded on the magnetic tape as one count at 2.19second intervals. The extra 0.19 seconds is required for electronic resetting of the equipment. The actual movement of the core during each 2.19 seconds is $3.46 \mathrm{~mm}$. 
Therefore each 2-second count samples a portion of the core length which is a moving average totaling about 1 $\mathrm{cm}$, and overlapping $(3.46 \mathrm{~mm})$ the intervals of the adjoining 2-second counts.

The data within the GRAPE system are continuously processed through Equation 15 by an analog computer, and then "immediately" recorded on an analog graph as "corrected" wet-bulk density. However, the new magnetic tape, with digital raw $I_{O}$ and $I$ data, is processed through Equation 15 at the shore-based computer facilities at Scripps Institution of Oceanography. The values of " $d$ " and " $\mu$ " used in these rough initial calculations are not significant as long as they are held constant (for example, $6.61 \mathrm{~cm}$ for $d$ and $0.100 \mathrm{~cm}^{2} / \mathrm{g}$ for the coefficient) as the data are internally calibrated with standards and processed in terms of ratios (see Appendix $\mathrm{E}$ for detailed derivation and equations used). The data are calibrated with a sea-water standard ${ }^{4}$ and an aluminum standard (Alcoa $1100-\mathrm{F}$, true density $=2.70$ $\mathrm{g} / \mathrm{cc}$ ), which are the same diameter as the core samples. The true densities for the sea water $\left(35 \mathrm{ppt}\right.$ at $\left.21^{\circ} \mathrm{C}\right)$ and aluminum standards are $1.025 \mathrm{~g} / \mathrm{cc}$ and $2.71 \mathrm{~g} / \mathrm{cc}$, respectively, with "corrected" densities of $1.128 \mathrm{~g} / \mathrm{cc}$ and $2.6 \mathrm{~g} / \mathrm{cc}$. Therefore, we have an analog graph, or magnetic tape, of the aluminum, sea water ${ }^{4}$ and the sediment sample, all calculated with Equation 15, thus the following ratio is possible:

$$
\frac{\rho_{b c}-\rho_{f c}}{\rho_{a c}-\rho_{f c}}=\frac{\rho_{b c s}-\rho_{f c s}}{\rho_{a c s}-\rho_{f c s}}
$$

where,

$\rho_{b c s}=$ is the analog line (in scale divisions) of the approximate "corrected" wet-bulk density of the sample calculated by Equation 15 and plotted on the GRAPE analog graph or approximate "corrected" density from the magnetic tape data.

$\rho_{f c s}=$ is the analog line (in scale divisions) of the aproximate "corrected" density of the sea water calculated by Equation 15 and plotted on the GRAPE analog graph or approximate "corrected" density value from the magnetic tape data.

\footnotetext{
${ }^{4}$ DSDP has substituted a 2.54-cm-diameter aluminum standard for the $6.61-\mathrm{cm}$ water standard so that samples may be run out of liners with standards out of liner (since Leg 18). For Leg 33 the "corrected" density for the $2.54-\mathrm{cm}$ aluminum standard is empirically calibrated as $1.03 \mathrm{~g} / \mathrm{cc}$, not $1.00 \mathrm{~g} / \mathrm{cc}$ as used on previous legs. Distilled water has been used in place of sea water in some standards with a true density of $1.00 \mathrm{~g} / \mathrm{cc}$ and a "corrected" density of $1.10 \mathrm{~g} / \mathrm{cc}$ (since Leg 16). When samples are in liner, the standards are in liner, and when samples are without liner, the standards are correspondingly without liner. In addition, small diameter $(5.71 \mathrm{~cm})$ punch cores have their own aluminum and distilled water standards $(5.71 \mathrm{~cm})$ inside punch core liner (since Leg 18). All of the interchanging of sea water, distilled water, and 2.54$\mathrm{cm}$ aluminum standards affect the value assigned to $\rho f_{c}(\rho f c s$ will be automatically affected as standard is run through the GRAPE) in Equation 25 only, where the "corrected" density of $1.128 \mathrm{~g} / \mathrm{cc}, 1.10$ $\mathrm{g} / \mathrm{cc}$, and $1.03 \mathrm{~g} / \mathrm{cc}$, respectively, would be substituted for $\rho_{f c}$.
}

$\rho_{\text {acs }}=$ is the analog line (in scale divisions) of the approximate "corrected" density of the aluminum calculated by Equation 15 and plotted on the GRAPE analog graph or the approximate "corrected" density value from the magnetic tape data.

$\rho_{a c}=$ aluminum density in $\mathrm{g} / \mathrm{cc}$ : "corrected" aluminum density as the aluminum has an attenuation coefficient differing from quartz.

Therefore we may now solve for the "corrected" wetbulk density of the sediment sample as follows:

$$
\rho_{b c}=\left[\frac{\left(\rho_{b c s}-\rho_{f c s}\right)\left(\rho_{a c}-\rho_{f c}\right)}{\left(\rho_{a c s}-\rho_{f c s}\right)}\right]+\rho_{f c}
$$

It follows from Equation 21 that the true wet-bulk density may also be calculated by the following equation:

$$
\rho_{b}=\left[\frac{\left(\rho_{b c}-\rho_{f c}\right)\left(\rho_{g}-\rho_{f}\right)}{\left(\rho_{g c}-\rho_{f c}\right)}\right]+\rho_{f}
$$

Porosity may be calculated by:

$$
\phi=\frac{\rho_{g}-\rho_{b}}{\rho_{g}-\rho_{f}}
$$

Equations 25 through 28 are the basis for the true GRAPE analog wet-bulk density data for DSDP Leg 33. ${ }^{5}$ The following parameters are used in Equations 25 through 27 and were selected on the basis of practicality and simplicity to make the data easy to manipulate: $\rho a c$ is $2.6 \mathrm{~g} / \mathrm{cc}, \rho_{f}$ is $1.128 \mathrm{~g} / \mathrm{cc}, \rho f$ is $1.025 \mathrm{~g} / \mathrm{cc}$, and $\rho g$ and $\rho g c$ are assumed to be $2.70 \mathrm{~g} / \mathrm{cc}$ for all sediments, except chert which is assumed to be $2.65 \mathrm{~g} / \mathrm{cc}$, and celestite which is assumed to be $4.34 \mathrm{~g} / \mathrm{cc} . \rho_{g}$ and $\rho_{g c}$ for basalt are assumed to be $2.86 \mathrm{~g} / \mathrm{cc}$.

\section{Actual Computer Computation of Legs 3 Through 11 Data:}

Equations 25 through 27 were also the basis for the true wet-bulk density plotted in the DSDP Legs 3 through 11 . The wet-bulk density used was obtained from Equation 27 assuming a grain density of $2.6 \mathrm{~g} / \mathrm{cc}$. Porosities were calculated (Equation 28) from the true wet-bulk density obtained in Equation 27, but using estimated grain densities, e.g., $2.71 \mathrm{~g} / \mathrm{cc}$ for calcite ooze. The grain density used to calculate porosity in DSDP legs can be determined by using Equation 28 (first change \% porosity to decimal form by dividing by 100 ) and solving for the unknown of grain density. If an investigator has more accurate grain density data, the data can be recalculated.

In order to minimize computer computation time for Legs 3 through 11 , or obtain data aboard ship, all computations of Equations 25 through 27 were reduced to a

\footnotetext{
'These equations will be subsequently used for all DSDP routine GRAPE data. The use of these equations actually began on Leg 29 and the results are essentially identical with Whitmarsh iteration data.
} 
simple linear interpolation between the aluminum standard and the sea-water standard, with a "corrected" density of $2.6 \mathrm{~g} / \mathrm{cc}$ assigned to the aluminum, and a true density of $1.025 \mathrm{~g} / \mathrm{cc}(1.03 \mathrm{~g} / \mathrm{cc}$ rounded off) assigned to the sea-water standard. This results in a true wet-bulk density value with an assumed grain density of $2.6 \mathrm{~g} / \mathrm{cc}$ and an assumed bulk grain attenuation coefficient of quartz.

The derivation of this linear interpolation technique and its equivalence to Equations 25 through 27 when using a $2.6 \mathrm{~g} / \mathrm{cc}$ grain density, is as follows: The key to the derivation is that $2.6 \mathrm{~g} / \mathrm{cc}$ grain density happens to be the same value as the "corrected" density of the aluminum standard. Therefore, this technique will not work with any other grain density value (unless assigned new "corrected" density to the standard by using a different attenuation coefficient other than that of quartz, which at present is not desired). Thus from Equations 25, 20, and 18:

$\frac{\rho_{g}-\rho_{b}}{\rho_{g}-\rho_{f}}=\phi=\frac{\rho_{g c}-\rho_{b c}}{\rho_{g c}-\rho_{f c}}=\frac{\rho_{a c}-\rho_{b c}}{\rho_{a c}-\rho_{f c}}=\frac{\rho_{a c s}-\rho_{b c s}}{\rho_{a c s}-\rho_{f c s}}$

Since a $2.6 \mathrm{~g} / \mathrm{cc}$ grain density is assumed then $\rho_{g}, \rho_{g c}, \rho_{a c}$, and $\rho_{a c s}$ all happen to be equivalent to $2.6 \mathrm{~g} / \mathrm{cc}$. Therefore, from Equations 25, 26, and 27 the following is true for the special case of $\rho_{a c}=\rho_{g}$ of $2.6 \mathrm{~g} / \mathrm{cc}$ :

$$
\rho_{b}=\left[\frac{\left(\rho_{b c s}-\rho_{f c s}\right)\left(\rho_{a c}-\rho_{f}\right)}{\left(\rho_{a c s}-\rho_{f c s}\right)}\right]+\rho_{f}
$$

Equation 30 is the actual formula used to determine true wet-bulk density from the GRAPE equipment and analog data from Legs 3 through 11. That true wet-bulk density was then used to calculate porosity as follows:

$$
\phi=\left[1-\frac{\left(\rho_{b}-\rho_{f}\right)}{\left(\rho_{g}-\rho_{f}\right)}\right] \times 100=\%
$$

\section{Analog GRAPE Geometric Adjustments and Sampling Problems}

In general, the GRAPE data assumes the GAMMA RAY PATH LENGTH through the sample is the internal diameter of the core liner, however, this assumption is not true when stiff sediment or rocks are cored without plastic flowage of the sample. Since the inside diameter of the drill bit is smaller (about $12 \%$ ) than that of the core liner $(6.61 \mathrm{~cm})$, the hard sediment sample or rock also has that smaller irregular diameter with the remaining space being filled with drilling slurry or highly disturbed sediment, water, or in some cases air. In addition, in some instances the rock core is not centered in the core liner, therefore the gamma beam is through some distance which is less than the diameter of the rock. On Leg 33 adjustments to these problems have been applied as discussed below.

\section{Rock Diameter Smaller Than Internal Diameter of Liner}

When stiffer sediment and rock are cored by DSDP, the rock cores have smaller diameters than the internal diameter of the liner, and are surrounded by slurry, paste, water, or air. Since the GRAPE measurement assumes the gamma-ray path length is the internal diameter of the core liner, and that there is no paste or slurry around the sample, thus an adjustment must be applied to obtain the true "corrected" wet-bulk density. These data can be adjusted by measuring the wet-bulk density of the sediment slurry or paste around the rock, and measuring the diameter of the hard rock (Figure 9). Approximate adjustments are calculated as follows:

$$
\begin{gathered}
100 A=[D(100-x)]+\mathrm{Sx} \\
D=\frac{100 A-S x}{100-x}
\end{gathered}
$$

where,

$$
\begin{aligned}
A= & \text { approximate "corrected" wet-bulk density } \\
& \text { calculated by the GRAPE assuming the gamma- } \\
& \text { ray path length is equal to the internal diameter } \\
\text { of the core liner (Equation } 26) . & \\
D= & \text { true "corrected" wet-bulk density }\left(\rho_{b c}\right) \text { of cen- } \\
& \text { tral hard rock " } \\
S= & \text { drilling slurry "corrected" density } \\
x= & \text { the percentage that the GAMMA RAY PATH } \\
& \text { LENGTH' through the hard sediment or rock is } \\
& \text { smaller than the internal diameter of the liner } \\
& (6.61 \mathrm{~cm})
\end{aligned}
$$

All "gamma ray path length" adjustments in Equations 33 and 34 (below) should be applied to the Evan's (1965) "corrected" density data ( $\rho_{b c}$ from Equation 26 ), prior to applying adjustments for the sea-water coefficient with Equation 27.

If samples have been removed from the liners and then processed through the GRAPE, and the sample diameter differs from that of the $2.6-\mathrm{g} / \mathrm{cc}$ aluminum standard, then the following diameter adjustments should be applied:

$D=A\left[\frac{(\text { diameter of } 2.6 \mathrm{~g} / \mathrm{cc} \text { aluminum standard })}{\text { (gamma-ray path length) }}\right]$

where,

$$
\begin{aligned}
D= & \text { the true sample "corrected density } \\
A= & \text { approximate "corrected" wet-bulk density ob- } \\
& \text { tained from the standards assuming the sample } \\
& \text { has the same diameter as the } 2.6-\mathrm{g} / \mathrm{cc} \text { aluminum } \\
& \text { standards }\left(\rho_{b c} \text { from Equation } 26\right) .
\end{aligned}
$$

\footnotetext{
${ }^{\circ}$ Gamma Ray Path Length = rock diameter if the diameter is aligned with the gamma beam, or $=$ Equation 36 (below) if diameter is not aligned with the gamma beam.
} 

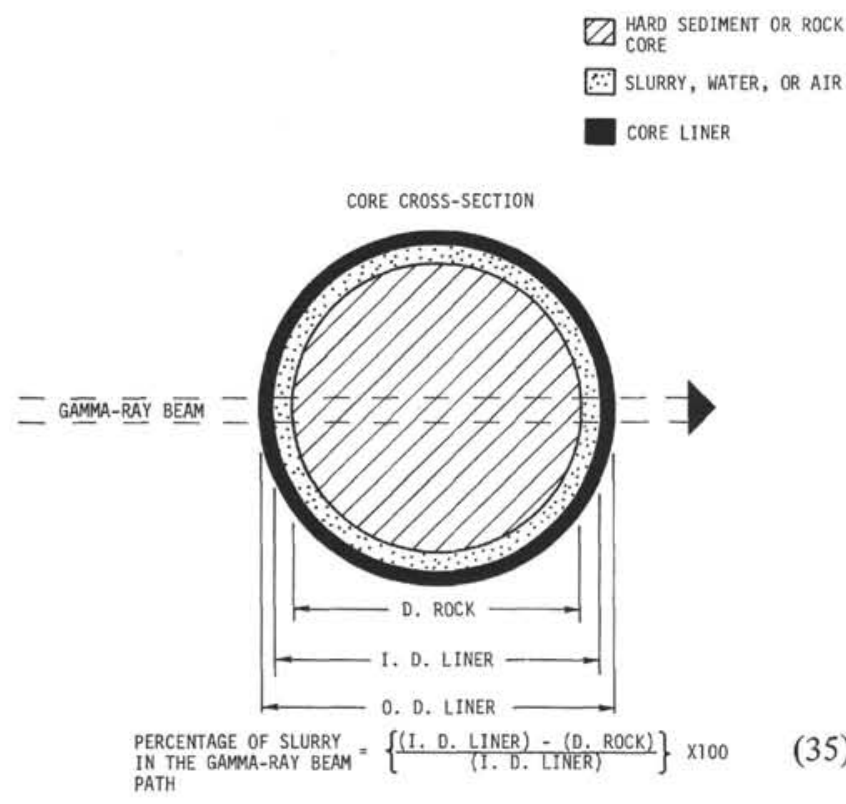

Figure 9. Cross section of hard sediment or rock core surrounded by sediment slurry in core liner. Derivation of percentage of slurry in gamma ray beam path is shown.

Gamma Ray Path Length = sample diameter, if the diameter is aligned with the gamma beam, or = Equation 36 if diameter is not aligned with gamma beam as discussed below.

\section{Core Diameter Offset \\ From Gamma Beam}

Another adjustment must be made in DSDP analog data if the stiff sediment or rock core is not centered in the liner allowing gamma rays to pass through the core off center and the path length is no longer the diameter of the sample, as in Figure 10. The true gamma-ray path length through the sample may be calculated by:

$$
\text { gamma ray path length }=2 \sqrt{r^{2}-b^{2}}
$$

where,

$$
\begin{aligned}
r= & \text { radius of hard rock } \\
b= & \text { amount hard rock offset from center of gamma } \\
& \text { beam, which for leg } 33 \text { hard rock cores which } \\
& \text { were without liners = (radius of } 2.6 \mathrm{~g} / \mathrm{cc} \text { alumi- } \\
& \text { num standard)-(radius of rock core) }
\end{aligned}
$$

All hard rock on Leg 33, which were run out of liner, were not aligned with the gamma beam, therefore the gamma beam did not pass through the rock diameter. All rocks and standards were run through the GRAPE while resting on a strip of liner, this insured that the standards had their diameters aligned with the gamma beam. Therefore, the amount of offset from the gamma beam to the diameter of the hard rock is equal to the radius of the $2.6-\mathrm{g} / \mathrm{cc}$ aluminum standard minus the radius of the rock sample. All rock diameters were measured on Leg 33.

For Leg 33 data all rock diameters were measured by hand, usually one measurement per short core segment,

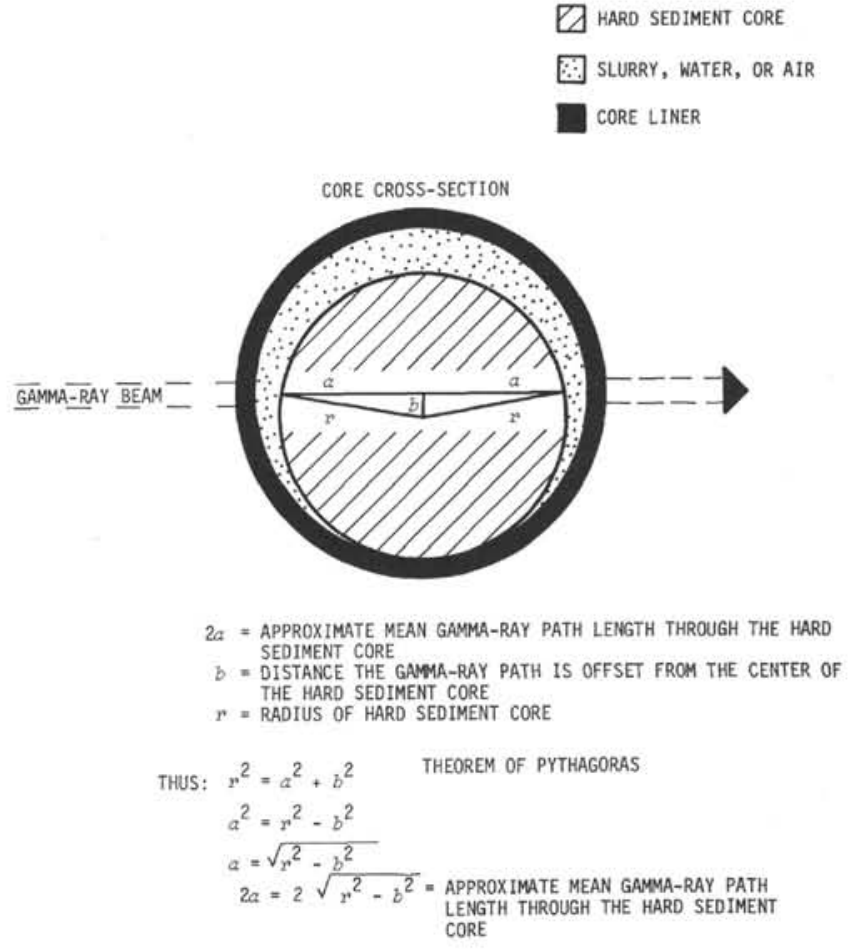

Figure 10. Derivation of true gamma ray path length through a hard sediment core which is not centered with respect to the gamma ray beam.

or approximately one measurement per $10-\mathrm{cm}$ interval on longer core segments. These rock segments are fairly rough, \pm 2 or $5 \mathrm{~mm}$; therefore, diameter measurements do not have a great amount of precision, but the statistical accuracy is helped by $15 \%$ to $20 \%$. These diameter adjustments were applied to the magnetic tape data by the shore-based computer facilities.

Another problem was matching the hand-measured diameter values to the proper depth interval on the magnetic tape data, which in some cases had discrepancies of $5 \mathrm{~cm}$ or more. Therefore the unadjusted GRAPE data $\left(\rho_{b}\right)$ were plotted as a solid line with the diameter adjusted GRAPE data $\left(\rho_{b}\right)$ as a dotted line. This allowed obvious errors to be corrected by hand using sno-pak and an ink pen. More importantly, this presentation allows the investigators to manipulate the data. Investigators interested in the density of a specific layer or rock piece should check the sample diameter from the core photograph or check the diameter file at Scripps, and see Appendix B for cores which were in or out of liner; and surrounded with air, water, or slurry, and make the appropriate diameter correction with the density value of the solid line as follows. Select an erroneous "true" density value without diameter adjustment, which is the solid black analog line. If the sample is a rock segment then select the maximum density value of the analog peak, then recalculate the unadjusted "corrected" density value by rearranging and resolving Equation 27, or use the nomogram in Figure 2 by going from the "true" density to the "corrected" density. Take that unadjusted "corrected" density value and apply the diameter adjustments from Equations 33, 34, 36, and 37. Then take 
this new diameter adjusted "corrected" density value and recalculate the diameter adjusted "true" density by Equation 27, or use the nomogram in Figure 2 by going from "corrected" density to "true" density.

\section{Subjective Interpretation of GRAPE Analog Data}

The GRAPE analog data are not objective pieces of data which can be used with ease, but instead they are data which must be subjectively analyzed and interpreted. The GRAPE analog data must be viewed with caution as they are the result of continuous density scanning along the diameter of (1) an unopened core which includes undisturbed sediment, disturbed sediment, and drilling slurries, or (2) along an opened core with the disturbed sediment cleaned off, but still scanning irregular and roughly cylindrical pieces of rock, typically 5 to 20 $\mathrm{cm}$ in length.

The core photographs should be studied carefully to determine the condition of the cores, both hard rock and soft sediment. With hard rock samples it is necessary to determine and select density data where the geometry of the rock is most advantageous and discard the analog data across rubble of small core segments or rock fragments. It may be necessary to apply proper GAMMA RAY PATH LENGTH adjustments as discussed in the section on "Analog GRAPE Geometric Adjustments and Sampling Problems." The soft sediments should be carefully studied in order to carefully select useful density data where the sample is not disturbed, or at best where disturbance is at a minimum. However, if a disturbed sample is selected, then one must assume that water has not been added or subtracted in order to use the data as characteristic of in situ conditions. This assumption may or may not be true depending on the conditions.

Recovery of unlithified sediments from the tops of the holes, usually the first 200 to 400 meters, are usually core disturbed sediment with soupy sediment strewn down the sides of the core. This latter is included in the GRAPE analog sample and there the analog density is typically less than the density of the samples taken from the sediment in the center of the core. Disturbance variation can also be seen within single cores as the tops of the cores tend to be more disturbed than the lower sections in the cores.

Frequently, when the sediments being drilled are firm, the coring sometimes recovers lumps of firm sediment alternating with soft sediment or a drilling slurry. This is observed in the GRAPE data as alternating high and low densities or just a sequence of high density peaks.

Because of the nature of the GRAPE analog data with 5 to $20 \mathrm{~cm}$ long rock segments, which appear as series of thin to wide density spikes, only the maximum density data at the tips of the spikes are probably valid data, as the remaining top and bottom "tails" are artifacts of the analog form of data when the density scan changes from air, water, or sediment slurry, to solid rock. Minimum wet-bulk density values and maximum porosity values are always suspect of being disturbed sediment, rock fragment, or drilling slurries.

Investigators interested in densities of specific layers which already have geometric adjustments applied (dotted line) on Leg 33 should recheck these adjustments using diameter data in core photos and the geometric condition discussed and listed in Appendix B. This check is advisable because of difficulties in precisely matching the measured diameters to the correct interval on the magnetic tape data. These are thoroughly discussed in the previous section of "Analog GRAPE Geometric and Sampling Problems" and therefore will not be discussed further here.

Geometric adjustments for small diameters of hard sediments or rocks have not been applied to the GRAPE data in past DSDP volumes, unless specifically stated. (Volumes 15, 31, and 33 are the only volumes to do so at present.) Therefore, the reader should judiciously consult the core photographs where an approximate diameter may be obtained (subject to some error if core is not split down the center or if the diameter of the rock is not aligned in the gamma beam, which can be calculated with Equation 36) or measure actual core diameters in the repositories. It will be necessary to recalculate the "corrected" wet-bulk density, apply diameter adjustments, then reapply adjustments for the water attenuation coefficient (Equation 26) to attain true wet-bulk density (see previous section "Analog GRAPE Geometric Adjustments and Sampling Problems").

Diameters or gamma-ray path lengths of the hard rock being processed through the GRAPE, are now measured by the GRAPE Russill calipers or by hand in order that some appropriate adjustments can be applied (see Appendices A and B).

\section{Summary and Discussion of GRAPE Analog Problems}

The Evans (1965) "corrected" wet-bulk density of saturated sediment can be determined by its attenuation of controlled gamma radiation by Equation 15 provided the empirical compton mass attenuation coefficient for quartz is known. Empirical coefficients are routinely determined by varying thicknesses of aluminum standards. In addition, spot checks are made with water and quartz standards. The major factor controlling the precision of these wet-bulk density determinations is related to random bursts of gamma rays emitted from the ${ }^{133} \mathrm{Ba}$ source, which causes a range in the density data of $\pm 6 \%$ with a standard deviation as great as $\pm 2 \%$, when a 2 -second counting period is used.

True wet-bulk density can be determined from the Evans (1965) "corrected" density by Equations 19 and 27 with an accuracy of $0 \%$ to $2 \%$ depending on the accuracy of the true and "corrected" grain and fluid densities used in the equation. The accuracy of these densities depends on the knowledge of the theoretical attenuation coefficients of minerals, or their electron densities. Basically these errors occur at $0 \%$ porosity and decrease to zero as the porosity increases to $100 \%$.

Porosity determined by Equation 28, using the true wet-bulk density, is subject to great error unless grain densities supplied to Equation 28 are accurately known. Therefore, unless the grain densities used were measured accurately, the low porosity values from only the GRAPE data are rough approximations. The error is greatest at $0 \%$ porosity, but the error decreases to zero as the porosity increases to $100 \%$. 
The above-stated accuracy and precision of the wetbulk density data are only valid assuming no errors result from attenuation coefficients of various minerals, resolution, liner variation, the gamma-ray path length, quality of the samples, all of which are briefly discussed below. If an effort is made to overcome these problems, as on Leg 33 , the resulting error is about $\pm 11 \%$ (see Table 14).

\section{Attenuation Coefficient Error}

A basic potential error is the assumption that all of the mineral grains in the sediment fraction have the same attenuation coefficient as that of quartz. This error for a given sediment obviously is systematic. See tables in Harms and Choquette (1965) for "corrected" densities. Here are a few examples, with their systematic error in parenthesis, if that mineral formed a rock with $0 \%$ porosity: montmorillonite $(-0.13 \mathrm{~g} / \mathrm{cc})$, chlorite $(-0.21 \mathrm{~g} / \mathrm{cc})$, orthoclase $(-0.07 \mathrm{~g} / \mathrm{cc})$, albite $(-0.07 \mathrm{~g} / \mathrm{cc})$, anorthite $(-0.06 \mathrm{~g} / \mathrm{cc})$, barite $(-0.52 \mathrm{~g} / \mathrm{cc})$, gypsum $(-0.33$ $\mathrm{g} / \mathrm{cc})$, halite $(-0.10 \mathrm{~g} / \mathrm{cc})$, sylvite $(-0.08 \mathrm{~g} / \mathrm{cc})$, pyrite $(-0.94 \mathrm{~g} / \mathrm{cc})$, etc. The value in parenthesis is equal to the "corrected" mineral density minus the true mineral density, and it indicates the absolute error (at zero porosity) if a quartz attenuation coefficient is used in Equation 15 to determine the density of that mineral.

\section{Resolution}

Resolution of the GRAPE analog density data depends on the diameter of the gamma-ray beam that passes through the sample and is received by the scintillation detector, and in addition, to the rate that the core carriage travels. The gamma-ray beam is about the size of a pencil across the diameter of the core, and the core moves lengthwise at a rate of $3.17 \mathrm{~mm} / 2$ seconds. Therefore the sampled portion of the core is a moving average of about $1 \mathrm{~cm}$ along the length of the core, which is measured for a 2.0 -second period. This occurs every 2.19 seconds because a 0.19 second is added for electronic resetting of the equipment. The total interval traveled per 2.19 seconds is $3.46 \mathrm{~mm}$. Therefore, a single 2 -second count would be the width of the gamma-ray beam plus the travel of $3.46 \mathrm{~mm}$ during a 2.19 -second interval, making the resolution about 1.0 to $1.3 \mathrm{~cm}$. One can find a demonstration of the resolution by observing the density changes at the boundaries of differing diameters of aluminum when the "aluminum telescope" is run in the pre- and postsite standards.

\section{Standards and $I_{O}$}

Since the DSDP analog GRAPE system uses standards, there is not a problem with the error of measuring $I_{O}$ (see Appendix E). Legs 1 through 17 used a 7-cm-long aluminum standard $(6.61-\mathrm{cm}$ diameter) and a $12-\mathrm{cm}-$ long water standard $(6.61-\mathrm{cm}$ diameter) from which 13 and 202 -second counts were used to obtain averages, respectively. These averages were from the center quartiles of the total length of each standard. The 7-cm-long aluminum standard $(6.61-\mathrm{cm}$ diameter) with a 132 second count should have means that are reproducible typically within $\pm 2 \%$ in terms of raw gamma counts (approximate total raw gamma count of 20,000 ) or $\pm 1.7 \%$ with respect to a density value of $2.6 \mathrm{~g} / \mathrm{cc}$. The 202 second counts of the $12-\mathrm{cm}$-long water standard (6.61$\mathrm{cm}$ diameter) should have means that are reproducible typically within $\pm 1 \%$ in terms of raw gamma counts (approximate mean gamma count of 85,000 ) or typically $\pm 1.5 \%$ with respect to a density value of $1.0 \mathrm{~g} / \mathrm{cc}$.

TABLE 14

Summary of GRAPE Data Error

\begin{tabular}{|c|c|c|c|c|}
\hline & \multicolumn{4}{|c|}{ Estimated Error } \\
\hline & \multicolumn{2}{|c|}{ Without Geometric Adjustments } & \multicolumn{2}{|c|}{ With Geometric Adjustments } \\
\hline & $\begin{array}{l}\text { @ } 1.025 \mathrm{~g} / \mathrm{cc} \\
(100 \% \text { porosity })\end{array}$ & $\begin{array}{l}\text { @ } 2.60 \mathrm{~g} / \mathrm{cc} \\
\text { (assume } 0 \% \\
\text { porosity) }\end{array}$ & $\begin{array}{l}\text { @ } 1.025 \mathrm{~g} / \mathrm{cc} \\
\text { (100\% porosity) }\end{array}$ & $\begin{array}{l}\text { @ } 2.60 \mathrm{~g} / \mathrm{cc} \\
\text { (assume } 0 \% \\
\text { porosity) }\end{array}$ \\
\hline $\begin{array}{l}\text { Random variation from } \mathrm{Ba}^{133} \\
\text { gamma-ray source: } 2-\mathrm{sec}\end{array}$ & $\pm 6 \%$ & $\pm 6 \%$ & $\pm 6 \%$ & $\pm 6 \%$ \\
\hline $\begin{array}{l}\text { Aluminum } 6.61-\mathrm{cm} \text { standard } \\
25 \mathrm{~cm} \text { long }\end{array}$ & $\pm 0 \%$ & $\pm 2 \%$ & $\pm 0 \%$ & $\pm 2 \%$ \\
\hline $\begin{array}{l}\text { Aluminum } 2.54-\mathrm{cm} \text { standard } \\
25 \mathrm{~cm} \text { long }\end{array}$ & $\pm 2 \%$ & $\pm 0 \%$ & $\pm 2 \%$ & $\pm 0 \%$ \\
\hline Attenuation coefficient & $?$ & $?$ & 0 & 0 \\
\hline Grain density of $2.6 \mathrm{~g} / \mathrm{cc}$ & assumed 0 & $\pm 2 \%$ & measured 0 & 0 \\
\hline Liner wall variation & $\pm 2 \%$ & $\pm 0.7 \%$ & $\pm 2 \%$ & $\pm 0.7 \%$ \\
\hline Diameter $^{\mathrm{a}}$ : assume $12 \%$ small & 0 & $-12 \%^{\mathrm{a}}$ & 0 & $\pm 2 \%$ \\
\hline $\begin{array}{l}\text { Gamma-ray beam not through } \\
\text { diameter of core: assume } \\
\text { diameter } 12 \% \text { to small }\end{array}$ & 0 & $-2 \%$ & 0 & $\pm 0.5 \%$ \\
\hline Summary: Per 2-sec count & $\pm 10 \%$ & $-12 \%^{\mathrm{a}} \pm 13 \%$ & $\pm 10 \%$ & $\pm 11 \%$ \\
\hline $\begin{array}{l}\text { Resolution per 2-sec count }= \\
1.3 \mathrm{~cm} \text { along length of core }\end{array}$ & & & & \\
\hline
\end{tabular}

${ }^{a}$ This assumes a uniform core $12 \%$ smaller than the liner. This error is much greater with odd pieces, and when the bit wears out. Thus, judicious selection of data is critical. 
From Leg 18 to the present, standards are $25 \mathrm{~cm}$ long and from each standard an average of 602 -second counts is used. The means of the 602 -second counts should be reproducible typically within $\pm 1 \%$, both in terms of density and raw gamma counts. The total number of gamma counts for the 6.61-cm-diameter aluminum standard is approximately 90,000 and the approximate total number of gamma counts for the 6.61$\mathrm{cm}$-diameter water standard and 2.54-cm-diameter aluminum standard are approximately 260,000 .

Gamma counts through air, empty liner, or empty containers are measured for the $I_{O}$ of special samples for a total of 602 -second counts, thus the means of this 60 2 -second count, about 500,000 individual gamma counts, should be reproducible typically within $\pm 1 \%$. For a discussion of statistical limitations imposed by a random radioactive source see Brier et al. (1969).

\section{Liner Variation}

The normal liner has a varying wall thickness. Measurements from 12 liners indicate a wall thickness variation of 1.94 to $3.02 \mathrm{~mm}$ with a mean of approximately 2.37 to $2.75 \mathrm{~mm}$. The approximate internal diameter of the liner is about $6.61 \mathrm{~cm}$ (within $1.0 \%$ to $0.5 \%$ ). The error in assuming a constant diameter is probably quite great, especially if a core has been bent, is oval shaped, or is under pressure from gas, etc.

The punch core liner varies in wall thickness also. It is thicker than the normal liner and ranges from 2.84 to $3.20 \mathrm{~mm}$ with a mean about $3.055 \mathrm{~mm}$. The typical internal diameter is $5.71 \mathrm{~cm}$.

If a $6.61-\mathrm{cm}$-diameter aluminum is processed, through Equation 15, then the average "corrected" density is $2.60 \mathrm{~g} / \mathrm{cc}$ with corresponding $I$ and $I_{O}$ data. If the aluminum is in a liner and the $I_{O}$ is assumed to be through air, then the density calculated is $2.69 \mathrm{~g} / \mathrm{cc}$. If an aluminum is without a liner and the $I_{O}$ is counted through an empty liner, then the resulting density is 2.50 $\mathrm{g} / \mathrm{cc}$. Therefore, the total effect of the liner in the density calculations is approximately $0.10 \mathrm{~g} / \mathrm{cc}$. Thus, is an average liner represents $0.1 \mathrm{~g} / \mathrm{cc}$, then a liner wallthickness which varies from 2 to $3 \mathrm{~mm}$ about a mean of $2.5 \mathrm{~mm}$ represents a density error of approximately $\pm 0.02 \mathrm{~g} / \mathrm{cc}$.

\section{Error of Sample Geometry}

Geometry error with the hard sediment or rock includes diameter measurement, slurry densities, and if the core is aligned with the gamma-ray beam. If these parameters are not measured, then the errors may be as great as $12 \%$ to $20 \%$ low. Considering only diameter measurements, the uniform rock cores are typically $12 \%$ smaller than the internal diameter of the liner when the drill bit is in good condition (disregarding irregular pieces); however, in the lower parts of some holes the bit becomes worn and the diameter of the hard core becomes even smaller in some cases. Obviously these pieces have to be removed from the liner and run through the GRAPE, but in the past this has not been done, therefore large errors of $12 \%$ to $20 \%$ probably occur in many hard rock data, and the core photographs or the repository samples will have to be consulted to obtain the necessary diameter data for correction factors to be applied to past published data.

Other geometry problems occur when the diameters of the rocks are not aligned with the gamma-ray beam, and the following errors result. If rocks of $2.6 \mathrm{~g} / \mathrm{cc}$ density are processed through the GRAPE with a $12 \%$ diameter decrease from $6.61 \mathrm{~cm}$, and there is a $4-\mathrm{mm}$ misalignment to one side of the gamma-ray beam (assumes rock sets on the bottom of the liner), then the additional error is $-2 \%$ with air surrounding the rock, and $-1.1 \%$ with water surrounding the rock. Of course as the porosity increases the error decreases to zero at $100 \%$ porosity.

Errors after all geometry corrections are made, are probably within $\pm 2 \%$ if the parameters are actually measured. However most of the core segments are very rough $( \pm 3 \mathrm{~mm})$ therefore the diameter error can be significantly greater than $\pm 2 \%$.

With respect to sample thickness problems, we have found that with aluminum standards (assuming 2.60 $\mathrm{g} / \mathrm{cc}$ is the corrected density) the empirical quartz mass attenuation coefficients (Equation 23) vary about 3\% depending on the thickness of the sample (6.61 to 2.54 $\mathrm{cm})$. This problem is corrected for the GRAPE Special 2-Minute samples, but it is ignored in the routine GRAPE analog data where the error is about $0.7 \%$ per $\mathrm{cm}$ that the gamma-ray path length is less than $6.61 \mathrm{~cm}$. With the extremely rough rock core segments processed through the GRAPE analog this error is felt to be insignificant. Therefore, on Leg 33 no adjustments have been made for this problem in the analog data. Whether or not future legs will have an adjustment will be decided pending further study, when analog calipers are routinely used.

\section{Miscellaneous Problems with the Magnetic Tape}

The digital magnetic tape system, when counting gamma rays traveling through air, sometimes has 2second counts which go beyond the range of the counter, and when this happens the resulting density data have a high density spike. In addition to this, occasionally the magnetic tape system garbles the gamma counts on the tape, with high density spikes as a result. For Leg 33 data, all magnetic tape density graphs (core scale) were compared to the GRAPE analog graphs, and all spikes were deleted from the published magnetic tape plots (by sno-paking) if they were not on both records.

\section{Digitizing Error in Analog Records}

The GRAPE analog records are used as a backup to the magnetic system and are used to fill in where the magnetic tape data are lacking. They are digitized at a frequency of 800 points per 1.5 -meter core section (one point every $1.87 \mathrm{~mm}$ of core length). The density scale is divided into 250 scale divisions and is digitized to the nearest division $(0.01 \mathrm{~g} / \mathrm{cc})$.

\section{Averaging of Published Data}

Typical data point frequency of the published analog graphs are as follows: These data are published at the core level ( $9 \mathrm{~m}$ core length per page) with 160 points per 1.5 meter length. The data are averaged over a $0.94-\mathrm{cm}$ interval with the averages plotted in the center of these 
intervals. At present 150 points per 1.5 meter or one point per $1 \mathrm{~cm}$ is being plotted. This will allow worse case resolution of about $2 \mathrm{~cm}$, with the best being about $1.3 \mathrm{~cm}$ per 2 -second period.

In the past, these analog GRAPE data have also been plotted at the hole level (GRAPE analog was not published at a hole scale for Leg 33), of 0 to 400 meters or 0 to 800 meters per page, and density data for these plots have typically been averaged over a 15 to $18 \mathrm{~cm}$ interval, with the average value being plotted in the center of that interval. These hole averages are fine as long as the sediment in the section is homogeneous, undisturbed, and unbroken. However, if the core sections contain broken, short core segments of rock, then a serious problem exists in the accuracy of the averaged density value over that interval. Obviously, this averaged density value will be low, because it is biased by the gaps between the rock segments.

Investigators plotting GRAPE analog hard rock data versus hole depth, which are usually short core segments which alternate with air, slurry, or water, should not blindly average the analog data over a given centimeter interval, but they should select a few valid individual points from each core section, which is representative of the geologic material in the core, and plot these data versus hole depth.

\section{Judicious Selection of \\ Valid Data From Density Graphs}

Recovery from the top of the hole, the first 200 meters (?), is usually disturbed sediment with "soupy" sediment strewn down the sides of the core. This latter is included in the GRAPE analog sample, but the individual wetwater content samples are taken at the center of the core and do not include "soup." In addition, within single cores the top is more disturbed than the lower parts and thus, individual sample densities taken in the lower core sections tend to match the GRAPE data better than the data from the top core sections.

Since the cores include disturbed sediment, drilling slurry alternating with hard sediments or rocks, then obviously one should not accept the graphical data point blank without consulting the core photographs. Even after consulting the core photographs, one may still be in doubt as to what rock corresponds to what density line because the density analog graph is a continuous measurement along the cores before they are split lengthwise and after they are split lengthwise the pieces may be dragged to one end of the 1.5 meter section.

Good samples require judicious selection. If one made the generality that if the sediments or rocks are alternating with soft soupy drilling slurry, then when one is observing the analog graphs the maximum density spikes are the hard undisturbed core segments (minimum porosities) and are probably the valid data (as- suming all geometry sample correction factors have been applied). The minimum wet-bulk density values and maximum porosity values are always suspect of being disturbed sediment and drilling slurries.

\section{ACKNOWLEDGMENTS}

The digital magnetic tape equipment was designed and built by Mr. Peter Woodbury's computer group and Mr. Paul Porter's electonics group at DSDP. Mr. Lloyd Russill's assistance is appreciated in designing the "aluminum telescope standard" and the Russill Calipers. All computer programs were written and operated by Mr. Peter Woodbury, Mr. Steve Bearman, and Mrs. Barbara Long.

\section{REFERENCES}

Alder, H.L. and Roessler, E.B., 1962. Introduction to probability and statistics: San Francisco and London (W.H. Freeman and Co.).

Barnes, H., 1959. Apparatus and methods of oceanography: New York (Interscience Publisher, Inc.), p. 341.

Boyce, R.E., 1973. Appendix I. Physical property methods. In Edgar, N.T., Saunders, J.B. et al., Initial Reports of the Deep Sea Drilling Project, Volume 15: Washington (U.S. Government Printing Office), p. 1115-1128.

Brier, C., Bennin, R., and Rona, P.A., 1969. Preliminary evaluation of a core scintillation counter for bulk density measurement in marine sediment cores: J. Sediment. Petrol., v. 39, p. 1509-1519.

Evans, H.B., 1965. GRAPE-A Device for continuous determination of material density and porosity: SPWIA Logging Symp., 6th Ann., Dallas, Texas. Trans. v. 2, p. B1-B25.

Evans, H.B. and Cotterell, C.H., 1970. Gamma-ray attenuation density scanner. In Peterson, M.N.A., Edgar, N.T., et al., Initial Reports of the Deep Sea Drilling Project, Volume 2: Washington (U.S. Government Printing Office), p. $442-454$.

Hamilton, E.L., 1971. Prediction of in situ acoustic and elastic properties of marine sediments: Geophysics, v. 36, p. 266284.

Harms, J.C. and Choquette, P.W., 1965. Geologic evaluation of a gamma-ray porosity device: SPWLA Logging Symp., 6th Ann., Dallas, Texas, Trans., p. C1-C37.

Keller, G.H., 1965. Deep sea nuclear sediment density probe: Deep-Sea Res., v. 12, p. 373-376.

Meyers, P.V., van Sciver, W.J., and Richards, A.F., 1973. Theory of nuclear transmission densitometry applied to sedimentology and geotechnology: Unpublished manuscript.

Preiss, K., 1968. Nondestructive laboratory measurement of marine sediment density in a core barrel using gamma radiation: Deep-Sea Res., v. 15, p. 401-407.

Schlumberger, 1972. Log interpretation - Vol. 1 Principles: New York (Schlumberger Ltd.)

Tittman, J. And Wahl, J.S., 1965. The physical foundation of formation density logging (gamma-gamma): Geophysics, v. 30 , p. $284-294$

Wahl, J.S., Tittman, J., Johnstone, C.W., and Alger, R.P., 1964. The dual spacing formation density Log: J. Petrol. Tech., v. 16, p. 1411-1416. 


\section{APPENDIX A \\ INSTRUCTIONS AND DATA REDUCTION \\ USING THE RUSSILL CALIPERS}

The Russill Caliper consists of two mechanical arms which pivot on individual potentiometers, and they measure the actual gamma-ray length through the rock which is not necessarily the diameter. For Leg 33 these data were recorded on the GRAPE analog paper record. However this "gamma ray path length through the rock" data are recorded with a vertical offset (along the length of the core) with respect to the corresponding density data. This offset, which is variable depending on the arc swung by the caliper arms, can be calculated by the shore-based computer program. The Model I Russill Caliper was experimental and was used on Legs 33 through 37 . The Model II Russill Caliper first began its use on Leg 38 and will be used on subsequent legs.

It is planned that the GRAPE magnetic tape and caliper equipment will be taken off the ship during Leg 40 in order to interface the caliper with the magnetic tape, therefore Leg 42 should have the caliper data recorded on magnetic tape. In addition, the "GAMMA RAY PATH LENGTH" will be plotted on the GRAPE analog records. The following are the setup of the analog records and the techniques and calculations using the caliper data from the digitized analog diameter records or the diameter data on the future magnetic tape.

The blue recorder pen is used on the GRAPE analog recorder for the caliper data. Since the chart paper is in inches, part of the following discussion will be in terms of inches instead of metric units. The right hand (as seen coming from recorder) 2 inches $(5.0 \mathrm{~cm})$ of the chart paper is used for caliper data at a one to one scale. The left-hand side of the 2-inch $(5 \mathrm{~cm})$ strip represents a 1-inch $(2.54 \mathrm{~cm})$ diameter core and the right side represents a 3 -inch diameter core. The Russill Calipers are calibrated using the 1 -inch $(2.54 \mathrm{~cm})$ and 2.6-inch $(6.61$ $\mathrm{cm}$ ) diameter aluminum standards, which rest on a strip of plastic liner so that the diameters are aligned with the gamma beam and caliper arms. The 1-inch $(2.54 \mathrm{~cm})$ diameter aluminum calibrates the 1-inch $(2.54 \mathrm{~cm})$ line and the 2.6-inch $(6.61 \mathrm{~cm})$ diameter aluminum standard will be used to calibrate the 2.6 -inch $(6.61 \mathrm{~cm})$ line. These lines are adjusted on the recorder by using the two respective calibration plots on the chart recorder, while alternating the respective aluminum standards until the two lines are completely reproducible.

When a hard core is run outside of the core, the core is cleaned and placed on a strip of normal liner. The corresponding standards are also run out of their liner, and also placed on a strip of normal liner for proper height relative to the gamma beam and caliper arms. The 6.61$\mathrm{cm}$ and $2.54-\mathrm{cm}$ diameter standards will internally calibrate the calipers for every core. The shore-based computer program will determine and average the caliper reading for the 1-inch $(2.54 \mathrm{~cm})$ and $2.6-$ inch $(6.61 \mathrm{~cm})$ aluminum standards analog lines, respectively, and linearly interpolate between these to determine the true "gamma ray path length through the rock" sample as follows:

$$
\begin{array}{ll}
m_{0.61}= & \text { scale units on analog graph or magnetic tape for } \\
& 6.61-\mathrm{cm} \text { diameter aluminum standard. } \\
m_{2.54}= & \text { scale units on analog graph or magnetic tape for } \\
& 2.54-\mathrm{cm} \text { diameter aluminum standard. } \\
m x_{r}= & \text { scale units on analog graph or magnetic tape for rock } \\
& \text { sample } \\
6.61 \mathrm{~cm}= & \text { true diameter of } 6.61-\mathrm{cm} \text { aluminum standard } \\
2.54 \mathrm{~cm}= & \text { true diameter of } 2.54-\mathrm{cm} \text { aluminum standard } \\
R x_{L}= & \text { gamma ray path length through the rock sample, in } \\
& \text { cm. }
\end{array}
$$

$$
\begin{gathered}
\frac{R x_{L}-2.54 \mathrm{~cm}}{6.61 \mathrm{~cm}-2.54 \mathrm{~cm}}=\frac{m_{r}-m_{2.54}}{m_{6.61}-m_{2.54}} \\
R x_{L}=\frac{\left(m_{r}-m_{2.54}\right)(6.61 \mathrm{~cm}-2.54 \mathrm{~cm})}{m_{6.61}-m_{2.54}}+2.54 \mathrm{~cm}
\end{gathered}
$$

This gamma-ray path length through the rock sample can then be used to adjust (by Equation 34) the approximate "corrected" density of Equation 26 to the true "corrected" density. The true "corrected" density is then adjusted for the water attenuation coefficient by Equation 27.
In order to apply the $R x$ adjustment to the proper approximate "corrected" density value, we must allow for the vertical misalignment (along the length of the core) of the density data with respect to that of the caliper data. The misalignment is caused by the distance between the gamma-ray beam and the point where the caliper measures the $R x$ of the rock sample.

The Leg 33-37 Model I Russill Caliper is sketched in Figure 11, which shows the critical geometric dimensions of the caliper. The offset from the gamma beam depends on the arc swung by the caliper arms, for example, when a $6.61-\mathrm{cm}$ and $5.0-\mathrm{cm} R x$ are measured the offset from the gamma-ray beam varies from about 3.8 to $4.1 \mathrm{~cm}$, respectively. When working with the GRAPE paper analog data, add about $1.0 \mathrm{~mm}$ for the physical pen offset on the recorder to the $9.0 \mathrm{~mm}$ of graph paper offset, which represents the true physical offset on the core of $4.0 \mathrm{~cm}$. For future magnetic tape data, when the caliper data are recorded on magnetic tape, the pen offset will not be pertinent, only the caliper will be important.

The GRAPE magnetic tape data will have a caliper offset (along the length of the core) which can be defined mathematically as follows (derivation in Figure 12):

$$
z=t+k-\sqrt{k^{2}-\left(w-\frac{R x}{2}\right)}
$$

where,

$z=$ space between gamma beam axis and point of caliper measurement $^{7}$

$t=$ minimum offset of calipers to gamma beam

$k=$ length of caliper arm

$w=$ perpendicular distance from caliper pivot point to central axis of rock core.

The critical parameters of the Model I Russill Caliper, which was used on Legs 33 through 37, are shown in Figure 11 and are listed as follows:

$$
\begin{aligned}
& t=3.3 \mathrm{~cm} \\
& k=11.7 \mathrm{~cm} \\
& w=6.7 \mathrm{~cm}
\end{aligned}
$$

By substituting these parameters into Equation $40, z$ for Legs 33 through 37 Model I Russill Calipers can be calculated.

The critical parameters of the Model II Russill Caliper which will be used on Leg 38 and subsequent legs are shown in Figure 13 and are listed as follows:

$t=2.65 \mathrm{~cm}$

$k=16.1 \mathrm{~cm}$

$w=6.12 \mathrm{~cm}$

By substituting these parameters into Equation 40 the $z$ for Leg 38 and subsequent legs can be calculated.

Basically, the magnetic tape will record a diameter, gamma count, etc., alternating along the length of the magnetic tape. The computer program will calculate the midpoint position (along the length of the core) of the 2-second gamma count relative to the two positions of the diameter measurements on each side of the gamma count. A linear interpolation will be made between the two diameter measurements based on the relative position of the gamma count midpoint to the positions of the diameter measurements. If a diameter position aligns itself exactly with the midpoint of a 2 -second count, then that single diameter will be used in the density calculation. A similar application is valid for a digitized diameter analog record. The above technique is referred to as the Bearman technique after the originator.

\section{HAND-MEASURED DIAMETERS AND CORE LOG}

On Leg 33 in lieu of proper calipers, we kept a log which indicated if the cores in liners were (1) full with soft sediment and not requiring diameter adjustment, (2) full but containing hard rock core segments. The latter cores were sketched with the diameters of the segments inserted into the sketch and with a note being made whether the core

'For the analog graph data it is necessary to add $1.0 \mathrm{~mm}$ for pen offset to a $z$ which is scaled down to the scale of the analog paper. 


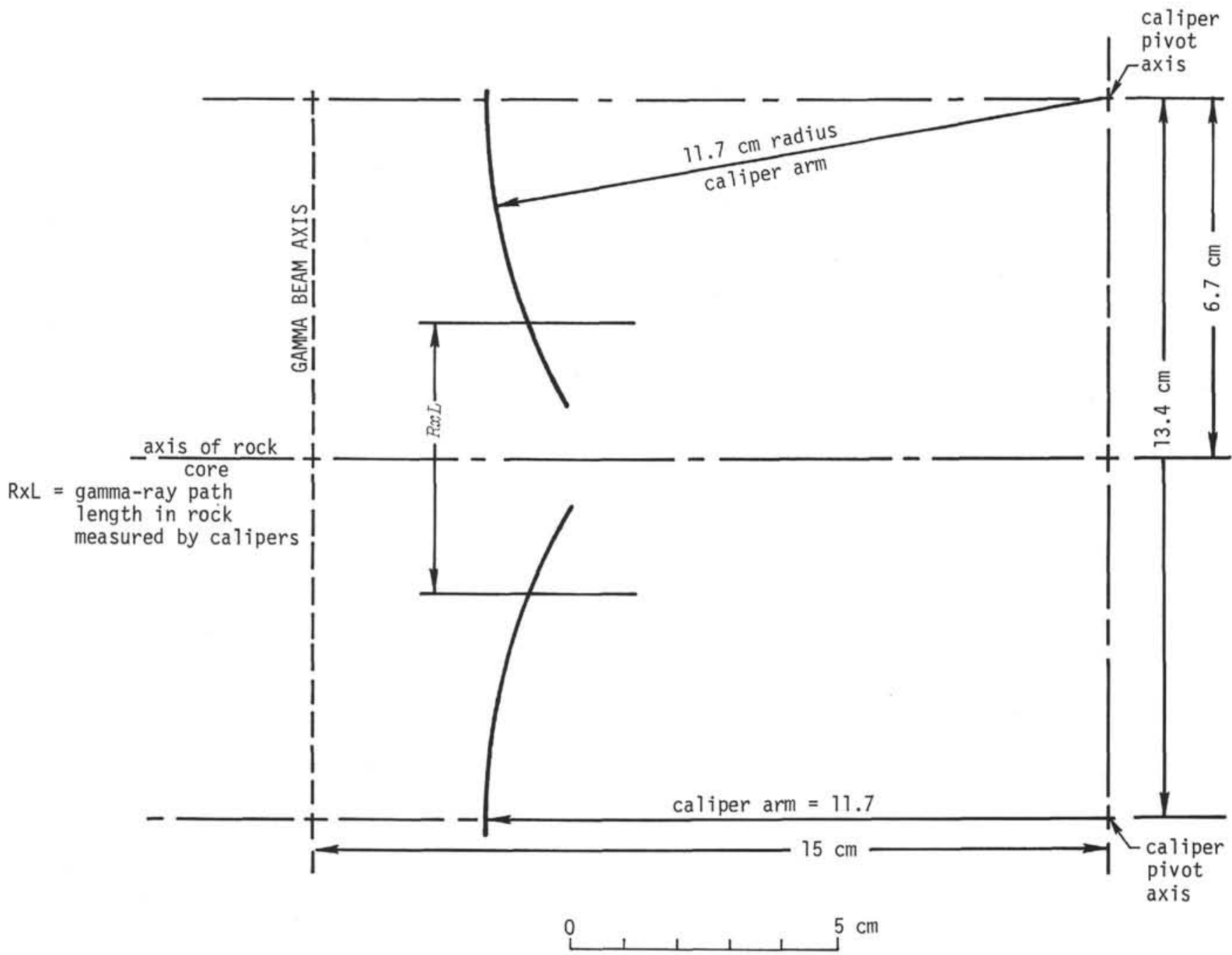

Figure 11. Critical geometric parameters of Leg 33-37 Model I Russill Calipers.

segment was surrounded by air, water, or slurry. If slurry was present, a syringe density was listed. If the diameter of the rock was offset from the axis of the gamma-ray beam, then the offset was measured. A diameter was measured for every core segment or about every $10 \mathrm{~cm}$. The third (3) geometric situation listed in the core log was if the rocks were run out of liners. The rocks run out of liners were also sketched with the diameters measured and written on the sketch. A diameter was measured for each rock segment or about every $10 \mathrm{~cm}$ on long core segments. The hard rock pieces by convention (on Leg 33) were lain on a strip of liner so that the offset between the gamma-beam axis and the diameter of the core was equal to the radius of the $6.61-\mathrm{cm}$ diameter standard minus the radius of the rock core.

In the future even when the calipers will be routinely used, it will be necessary to continue making a log for the soft and hard rock samples in liners, as the calipers will not be applicable. Leg 38 began using a table form of the log, instead of sketches, as it is more applicable to computerization.

Listed in Table 15 are the geometric states of the cores as they were run through the GRAPE on Leg 33 so that investigators may manipulate the data.

\section{APPENDIX C \\ ENERGY SPECTRUM ADJUSTMENT OF THE ${ }^{133}$ BARIUM GAMMA-RAY SOURCE}

The ${ }^{133}$ barium has a fairly complex spectrum of $0.032,0.057,0.080$, 0.300 , and $0.359 \mathrm{MeV}$. Theoretically we should be measuring only the 0.3 and $0.359 \mathrm{MeV}$ energy levels. The smaller $\mathrm{MeV}$ energies are cut off electronically by a "discriminator" that passes only pulses which are larger than some preset size. The following is how this is done with our system.

The lower energy levels are cut off by the "linear amplifier on the magnetic tape" equipment, but the Evans (1965) GRAPE equipment uses another pot within its system. This "threshold discriminator" is adjusted by counting in air, and turning the pot until no counts are measured. This "threshold discriminator" is then slowly and continuously lowered until the number of gamma counts begin increasing followed by a plateau where the number of gamma counts level off (the $0.359 \mathrm{MeV}$ energy level). As the threshold of the discriminator is continuously lowered, the gamma counts increase and a second plateau $(0.300 \mathrm{MeV}$ energy level) is observed. As the threshold is lowered more, the count begins to rise a third time, here the threshold lowering is stopped, and then it is raised until the counts return to the second plateau with the least amount of noise (just below $0.300 \mathrm{MeV}$ ).

\section{APPENDIX D \\ DSDP DIGITAL SYSTEM AND MAGNETIC TAPE ATTACHMENT TO THE GRAPE}

The DSDP Digital System and Magnetic Attachment to the GRAPE is shown in the block diagram of Figure 14. The scaler time is adjustable in 0.1 -second increments. It is normally placed on 2.0 seconds. With unusual or special samples it is possible to place it at 2.0

${ }^{8}$ The system was designed and built by Paul Porter and his electronics group and Peter Woodbury of the Computer Group at DSDP. 


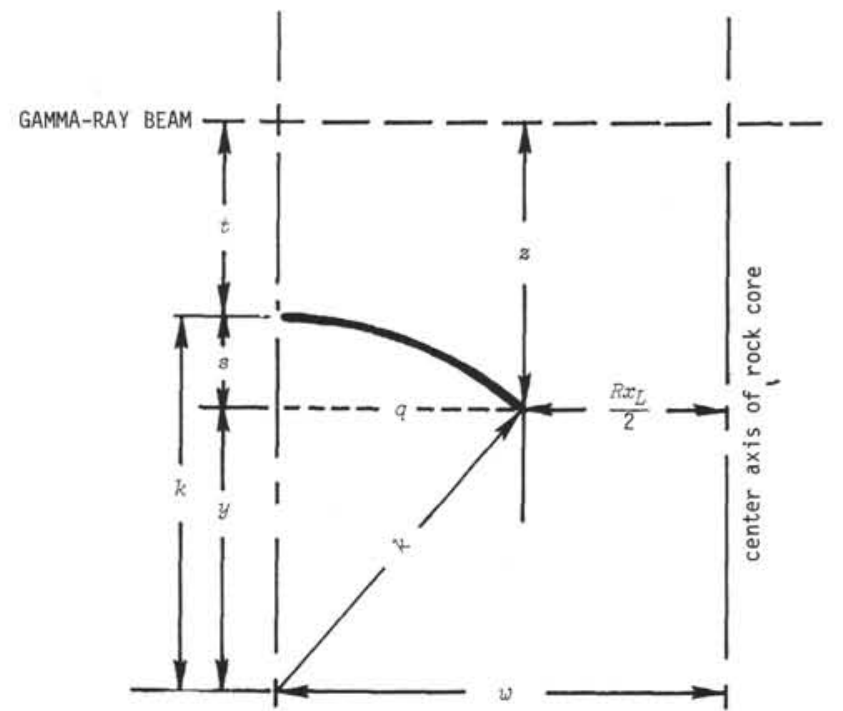

$t=$ minimum offset of the end of the calipers to the GAMMA BEAM $k=$ length of the caliper arm

$w=$ perpendicular distance from caliper pivot point to central axis of rock core

$R x_{L}=$ "gamma ray path length" through the rock core measured by calipers

Find: Space between gamma beam axis and point of caliper measurements, $a$.

Solution:

$k^{2}=y^{2}+q^{2} \quad$ Theorem of Pythagoras

$y=\sqrt{k^{2}-q^{2}}, q=w-\frac{R x_{L}}{2}$

$y=\sqrt{k^{2}-\left(w-\frac{R x_{L}}{2}\right)^{2}}$

$s=k-y=k-\sqrt{k^{2}-\left(w-\frac{R x_{L}}{2}\right)^{2}}$

$z=t+s=t+k-\sqrt{k^{2}-\left(w-\frac{R x_{L}}{2}\right)^{2}}$

Figure 12. Derivation of caliper distance to gamma ray beam axis.

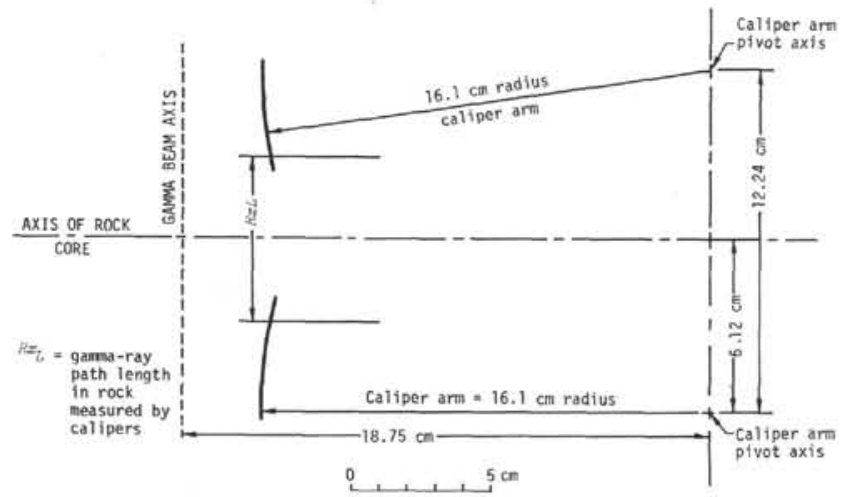

Figure 13. Critical geometric parameters of Leg 38 Model II Russell Calipers.

minutes. It has a visual digital display of each count, allowing density determination on individual samples without entering the data on the tape. The tape used is $556 \mathrm{BPI}$, seven (7) track magnetic incremental tape.
TABLE 15

Geometric Condition of Leg 33 Cores

As They Were Processed Through the GRAPE

\begin{tabular}{|c|c|c|c|c|}
\hline Hole & Core & Section & Interval & Geometric Condition $^{\mathrm{a}}$ \\
\hline 314 & & & & Soft sediment in liner \\
\hline 315 & & & & Soft sediment in liner \\
\hline \multirow[t]{7}{*}{$315 \mathrm{~A}$} & $1-3$ & & & Soft sediment in liner \\
\hline & 4 & $1-2$ & & $\begin{array}{l}\text { Soft and hard sediment } \\
\text { in liner }\end{array}$ \\
\hline & & & & $\begin{array}{l}\text { Slurry density }=1.5 \\
\mathrm{~g} / \mathrm{cc}, \text { no offset (?) }\end{array}$ \\
\hline & 4 & 3 & & Soft sediment in liner \\
\hline & $5-9$ & & & $\begin{array}{l}\text { Soft and hard sediment } \\
\text { in liner }\end{array}$ \\
\hline & & & & $\begin{array}{l}\text { Slurry density }=1.5 \\
\mathrm{~g} / \mathrm{cc} \text {, no offset (?) }\end{array}$ \\
\hline & $10-34$ & & & Hard rock out of liner \\
\hline \multirow[t]{4}{*}{316} & $1-2$ & & & Soft sediment in liner \\
\hline & $3-4$ & & & $\begin{array}{l}\text { Soft and hard sediment } \\
\text { in liner }\end{array}$ \\
\hline & & & & $\begin{array}{l}\text { Slurry density }=1.5 \\
\mathrm{~g} / \mathrm{cc}, \text { no offset (?) }\end{array}$ \\
\hline & $5-30$ & & & Hard rock out of liner \\
\hline \multirow{2}{*}{317} & $1-2$ & & & Soft sediment in liner \\
\hline & 3 & & & Hard rock out of liner \\
\hline \multirow[t]{3}{*}{$317 \mathrm{~A}$} & $1-2$ & & & Hard rock out of liner \\
\hline & 3 & & & Soft sediment in liner \\
\hline & $4-34$ & & & Hard rock out of liner \\
\hline \multirow[t]{4}{*}{$317 \mathrm{~B}$} & $1-16$ & & & Soft sediment in liner \\
\hline & 17 & & & Hard rock out of liner \\
\hline & $18-43$ & & & Soft sediment in liner \\
\hline & 44 & & & Hard rock out of liner \\
\hline \multirow[t]{18}{*}{318} & $1-8$ & . & & Soft in liner \\
\hline & 9 & 1 & $0-125$ & $\begin{array}{l}\text { Hard and soft sediment } \\
\text { in liner }\end{array}$ \\
\hline & & & & $\begin{array}{l}\text { Air around rock, off- } \\
\text { set }=3.305-\text { rock radius }\end{array}$ \\
\hline & 9 & 1 & $12-145$ & $\begin{array}{l}\text { Hard and soft sediment } \\
\text { in liner }\end{array}$ \\
\hline & & & & $\begin{array}{l}\text { Slurry density }=1.5 \\
\mathrm{~g} / \mathrm{cc}, \text { no offset }(?)\end{array}$ \\
\hline & 9 & 2 & $0-130$ & $\begin{array}{l}\text { Hard and soft sediment } \\
\text { in liner }\end{array}$ \\
\hline & & & & $\begin{array}{l}\text { Air around rock, off- } \\
\text { set }=3.305-\text { rock radius }\end{array}$ \\
\hline & 9 & 2 & $130-150$ & $\begin{array}{l}\text { Hard and soft sediment } \\
\text { in liner }\end{array}$ \\
\hline & & & & $\begin{array}{l}\text { Slurry density }=1.5 \\
\mathrm{~g} / \mathrm{cc}, \text { no offset (?) }\end{array}$ \\
\hline & $10-11$ & & & Soft sediment in liner \\
\hline & 12 & 1 & & Hard rock out of liner \\
\hline & 12 & 2 & & Soft sediment in liner \\
\hline & $13-14$ & & & Soft sediment in liner \\
\hline & 15 & 1 & & Hard rock out of liner \\
\hline & & 2 & & Soft sediment in liner \\
\hline & $16-18$ & & & Hard rock out of liner \\
\hline & 19 & & & Soft sediment in liner \\
\hline & $20-32$ & & & Hard rock out of liner \\
\hline
\end{tabular}

a Soft Sediment in Liner: Soft sediment completely filled the core liner and no diameter adjustments are necessary. Soft and Hard Sediment in Liner: Alternating soft sediment and hard rock segments in the core liner, with diameter adjustments applied for the hard rock segments. It is noted if the rock was surrounded by air, water, sediment slurry given. Hard Rock out of Liner: Hard rock core segments were removed from the core liners, cleaned, and placed on a strip of liner, and surrounded by air. The offset of the gamma beam axis and diameter of the hard rock $=3.305 \mathrm{~cm}$-radius of rock. 
Evans (1965) GRAPE Equipment

Marathon 0i1 Company

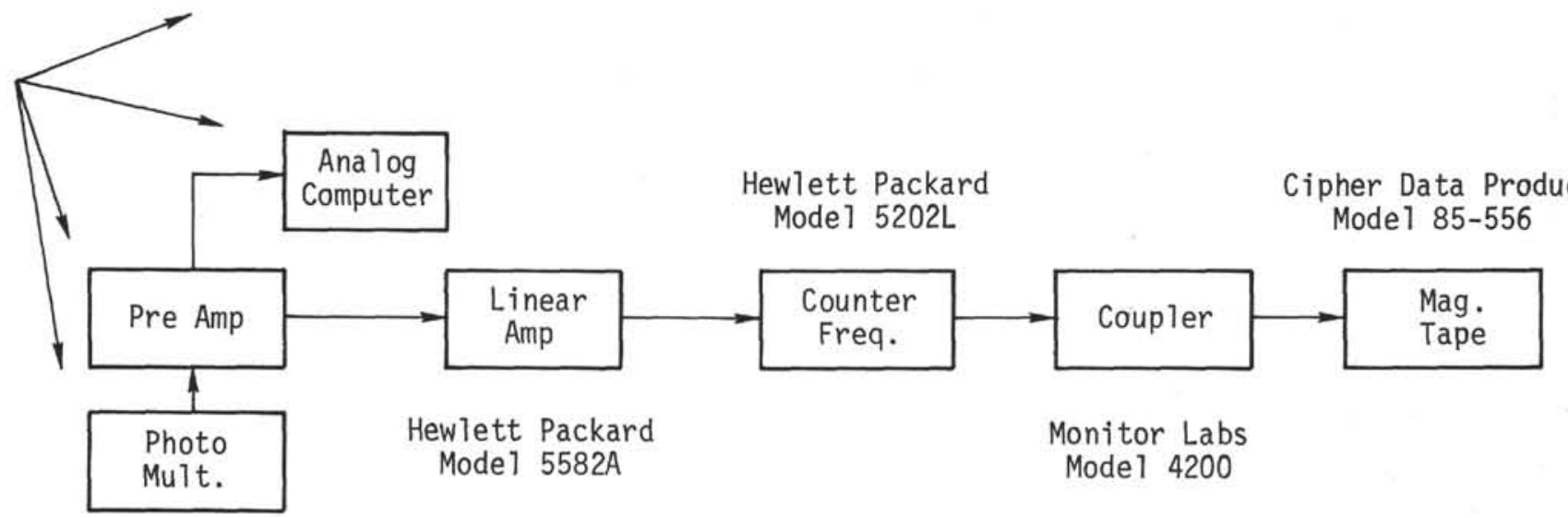

Figure 14. Block diagram of DSDP Digital System and Magnetic Tape Attachment to the GRAPE (Evans, 1965).

The magnetic tape is processed through the shore-based computer facilities and is not used at sea. The site, hole, core and section are placed in the label, with a code number to identify presite and postsite standards, routine standards, routine standards in liners, routine core samples in liners, punch core standards, punch core samples, standards without liners, samples without liners, and special data.

Labeling of a magnetic tape record requires the first nine (9) digits of the tape record. Reading from left to right, the first four switches or digits are set for hole or site number. The fourth digit of the site number is used to indicate A, B, etc. $1230=$ Site $123,1231=$ Site $123 \mathrm{~A}$, and $1232=$ Site $123 \mathrm{~B}$. The next three are for core number, and digit eight ( 8$)$ is for section number. The ninth digit is for the identification code.

As a convention, when standards and samples are in core liners, the GRAPE analog computer is nulled while counting through the empty liner. When standards and samples are without liners the GRAPE analog computer is nulled while counting through air.

All air, empty liner, routine aluminum, and water standards are measured for approximately 75 counts each. The only exception is the aluminum "telescope" (multidiameter aluminum) which is counted for a total of 270 counts. It is processed small end first and is $76 \mathrm{~cm}$ long and has diameters of $2.54,3.80,5.08$, and $6.66 \mathrm{~cm}$.

The different types of standards and samples and their identification are displayed in Table 16. These consist of presite and postsite standards, routine standards and samples $(6.61 \mathrm{~cm})$ inside liner; standards and samples without liners; punch core standards and samples (5.71 $\mathrm{cm}$ ) inside liners. The record length is the total number of counts allotted the standards or sample. After the system counts for the allotted record length, the system places a record gap on the tape, which marks the ending on one record and the beginning of a new record. The identification code set per standard or core as shown below, which has been in effect since Leg 29 (see Table 16):

$0=$ routine standards (run before each core)

$1=$ sample in liner

2 = standards without liner

3 = samples without liner

$4=$ standards for punch core with liners

$5=$ punch core sample in liner

6 = presite and postsite standards to be run at the beginning and completion of each site.

$7=$ presite and postsite standards to be run at the beginning and completion of each site.

8 = flags nonroutine data which will not be plotted as routine data: e.g., sound velocity samples or other unusual lithologic samples such as chert run without the carriage moving, or quartz and limestone standards, etc. documented in log book.

$9=$ to indicate that previous data record is to be aborted.

For codes of Legs 21-25 see Table 17 and Legs 26-28 see Table 18.

\section{APPENDIX E \\ MAGNETIC TAPE DATA: PREPROCESSING PRIOR TO EQUATIONS 25, 26, AND 27}

To calculate the corrected wet-bulk density, Equations 25 and 26 were originally adapted to apply directly to the GRAPE analog data, which are in units of density (Equation 15). The magnetic tape data, however, are just raw $I_{O}$ and $I$ gamma counts; therefore, before the corrected wet-bulk density and true wet-bulk density can be determined by Equations 25,26 , and 27 , the data must be recalculated into density values in a form and units similar to that of the GRAPE analog records.

The standard magnetic tape preprocessing procedure allows us to bypass the necessity of knowing exactly the $\mathrm{MeV}$ energy range of our ${ }^{133} \mathrm{Ba}$ source, which controls the apparent values of the mass attenuation coefficients, which are characteristic of only our GRAPE equipment. The log of the mass attenuation coefficient is a linear function with the log of $\mathrm{MeV}$ for most geologic material within the range of the ${ }^{133} \mathrm{Ba}$ source (see Evans, 1965, fig. 4). It is possible to determine some approximate corrected density value with an unknown (within 10\%) mass attenuation coefficient $\mu_{x}$ :

$$
\rho=\frac{\ln \left(I_{o} / I\right)}{\mu_{x} d}
$$

Let us assume that we process a $6.61-\mathrm{cm}$ diameter aluminum standard9 gamma count $I 0.61$ and a $2.54-\mathrm{cm}$ diameter aluminum standard $9 \mathrm{gam}$ ma count $I 2.54$, and the sample gamma count $I_{O}$, respectively, through the respective Equations 42,43 , and 44 below, and use a $d=6.61^{9}$ in all these equations.

$$
\begin{aligned}
\rho_{6.61 \mathrm{~cm} \mathrm{~A} 1} & =\frac{\ln \left(I_{o} / I_{a 6.61)}\right.}{\mu_{x} 6.61 \mathrm{~cm}} \\
\rho_{2.54 \mathrm{~cm} \mathrm{~A} 1} & =\frac{\ln \left(I_{o} / I_{a 2.54}\right)}{\mu_{x} 6.61 \mathrm{~cm}}
\end{aligned}
$$

'Diameter value of $6.61 \mathrm{~cm}$ is used, except with punch cores where $5.71 \mathrm{~cm}$ aluminum and distilled water standards are used. In this case $5.71 \mathrm{~cm}$ diameter value is used. 
TABLE 17

TABLE 16

Sampling, Labels, and Record Lengths Representing a Typical Standard and Sample Sequence of the Tape Records ${ }^{\mathrm{a}}$

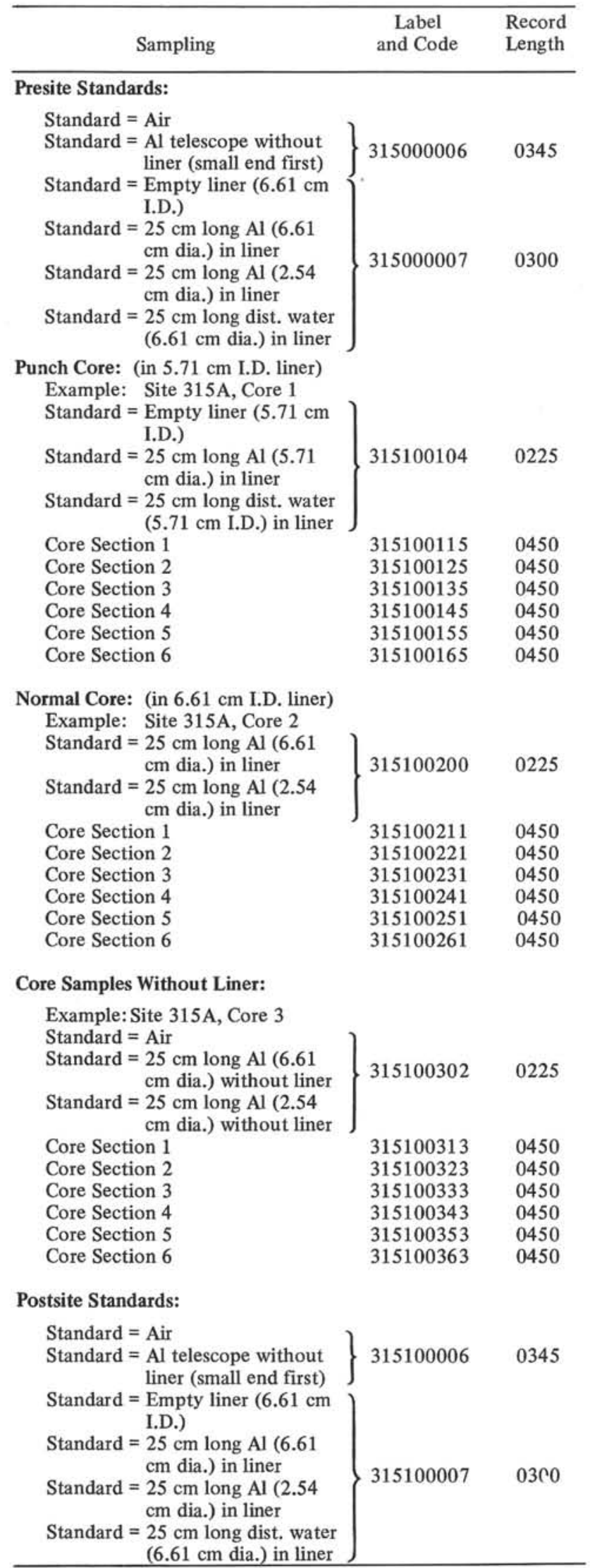

${ }^{\mathrm{a}}$ This coding has been in operation beginning with Leg 29 .
Magnetic Tape Codes Used During Legs $21^{\mathrm{a}}-25$

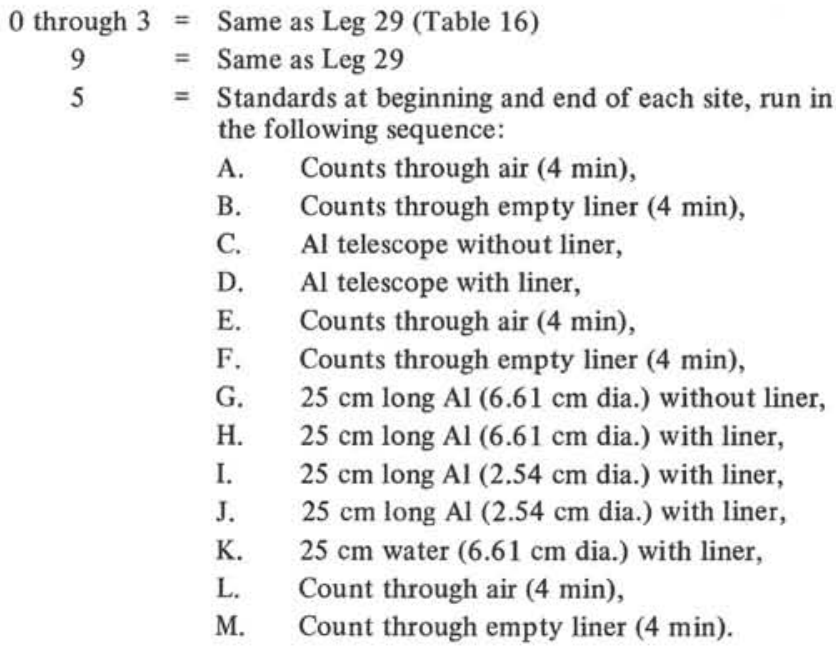

${ }^{\mathrm{a}}$ Leg 21 data codes may be garbled somewhat as experimenting was going on.

$$
\rho_{\text {sample }}=\frac{\ln \left(I_{o} / I_{s}\right)}{\mu_{x} 6.61 \mathrm{~cm}}
$$

The ratio of the densities obtained from Equations 42 and 43 will be constant regardless of the value of $\mu_{x}$, as long as $\mu_{x}$ remains a constant in both equations. Therefore, the empirical density values calculated with $\mu_{x}$ can be related to the theoretical densities with a theoretical $\mu$ of $0.1 \mathrm{~cm}^{2} / \mathrm{g}$ by the following ratios. The empirical ratios are equal to the theoretical ratios as follows:

EMPIRICAL RATIO

$$
\frac{\rho_{6.61 \mathrm{~cm} \mathrm{~A} 1}}{\rho_{2.54 \mathrm{~cm} \mathrm{~A} 1}}=\frac{\frac{\ln \left(I_{o} / I_{a 6.61}\right)}{\mu_{x} 6.61 \mathrm{~cm}}}{\frac{\ln \left(I_{o} / I_{a 2.54}\right)}{\mu_{x} 6.61 \mathrm{~cm}}}=
$$

is equal to,

\section{THEORETICAL RATIO}

$$
=\frac{\frac{1 \mathrm{n}\left(I_{o} / I_{a 6.61}\right)}{0.1 \mathrm{~cm}^{2} / \mathrm{g}(6.61 \mathrm{~cm})}}{\frac{\ln \left(I_{o} / I_{a 2.54}\right)}{0.1 \mathrm{~cm}^{2} / \mathrm{g}(6.61 \mathrm{~cm})}}=\frac{2.60 \mathrm{~g} / \mathrm{cc}}{1.00 \mathrm{~g} / \mathrm{cc}}
$$

The above ratios (Equation 45) and Equations 42 and 44 allow us to arbitrarily assign theoretical values of $2.60^{10}$ and $1.00 \mathrm{~g} / \mathrm{cc}^{10}$ to the $6.61-\mathrm{cm}$ and $2.54-\mathrm{cm}$ aluminum standards on the magnetic tape density data.

\footnotetext{
${ }^{10} \mathrm{The}$ values of 2.60 and $1.00 \mathrm{~g} / \mathrm{cc}$ assigned here actually control the value of the theoretical mass attenuation coefficient that the "corrected" density is relative to. This is described in Boyce (1973). The quartz attenuation coefficient is presently assigned in Equation 46 as shown above.
} 
TABLE 18

Magnetic Tape Codes for Legs 26-28

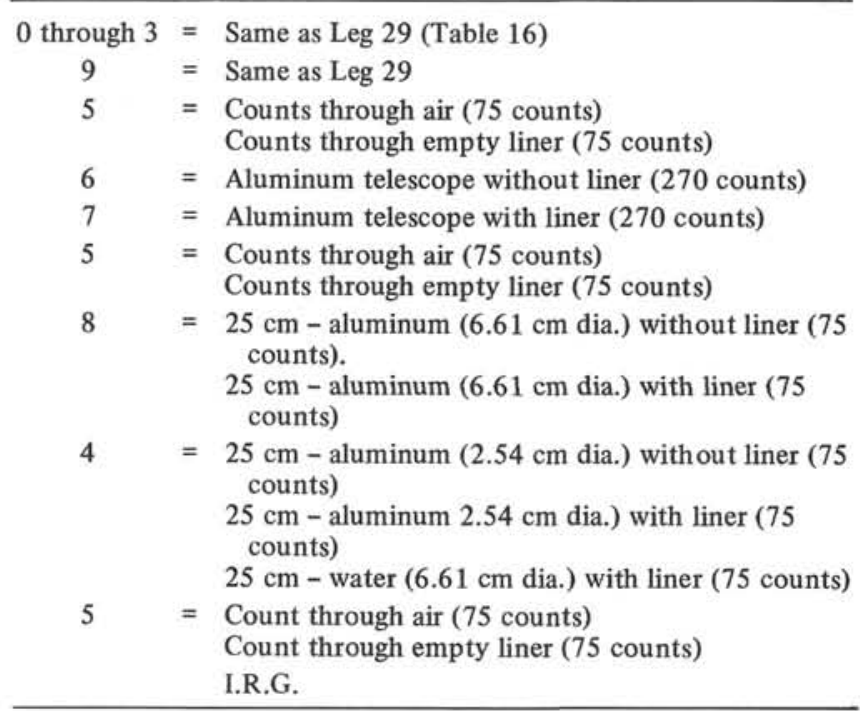

Note: Blank $=0, A=1, B-2$, etc, for site number.

The sediment sample "corrected" wet-bulk density data are processed through Equation 44 with the same arbitrary $\mu$ and then through ratios with respect to the aluminum standards to be relative to the theoretical "corrected" $2.6 \mathrm{~g} / \mathrm{cc}$ and $1.0 \mathrm{~g} / \mathrm{cc}$ values of the aluminum standards. The empirical ratios are equal to the theoretical ratios as follows:

\section{EMPIRICAL RATIO}

$$
\frac{\left[\frac{1 \mathrm{n}\left(I_{o} / I_{s}\right)}{\mu_{x} 6.61 \mathrm{~cm}}\right]-\left[\frac{\ln \left(I_{o} / I_{a 2.54}\right)}{\mu_{x} 6.61 \mathrm{~cm}}\right]}{\left[\frac{1 \mathrm{n}\left(I_{o} / I_{a 6.61}\right)}{\mu_{x} 6.61 \mathrm{~cm}}\right]-\left[\frac{1 \mathrm{n}\left(I_{o} / I_{a 2.54}\right)}{\mu_{x} 6.61 \mathrm{~cm}}\right]}=
$$

is equal to,

\section{THEORETICAL RATIO}

$$
=\frac{\left[\frac{\ln \left(I_{o} / I_{s}\right)}{0.1 \mathrm{~cm}^{2} / \mathrm{g}(6.61 \mathrm{~cm})}\right]-\left[\frac{1 \mathrm{n}\left(I_{o} / I_{a 2.54}\right)}{0.1 \mathrm{~cm}^{2} / \mathrm{g}(6.61 \mathrm{~cm})}\right]}{\overline{1 \mathrm{n}\left(I_{o} / I_{a 6.61}\right)}}
$$

is equal to,

$$
=\frac{\text { ("corrected" sample bulk density) }-1.00 \mathrm{~g} / \mathrm{cc}}{2.60 \mathrm{~g} / \mathrm{cc}}
$$

These empirical and theoretical ratios explain the reasoning of the preprocessing of the magnetic tape data, and also how we can assign $2.60 \mathrm{~g} / \mathrm{cc}$ and $1.00 \mathrm{~g} / \mathrm{cc}$ to the standards in the GRAPE analog data. However, in the actual Program the magnetic data standards and samples are recalculated by Equations 42,43 , and 44 , then the values of $2.60 \mathrm{~g} / \mathrm{cc}$ and $1.00 \mathrm{~g} / \mathrm{cc}$ are assigned to the standards, and then the sample "corrected" density is a linear interpolation between the stan- dards. The assigning of the 2.60 and $1.00 \mathrm{~g} / \mathrm{cc}^{\mathrm{I}}$ to the standards and the linear interpolation between the standards actually take place in Equation 25, which is represented as Equation 47 below. The following ratio is derived from Equation 46:

$$
\frac{\rho_{b c}-\rho_{a c 2.54}}{\rho_{a c 6.61}-\rho_{a c 2.54}}=\frac{\rho_{b s}-\rho_{a s 2.54}}{\rho_{a s 6.61}-\rho_{a s 2.54}}
$$

where,

$\rho_{b c}=$ any "corrected" sample density, $\mathrm{g} / \mathrm{cc}$

$\rho_{b s}=$ any sample data of magnetic tape data, $\mathrm{g} / \mathrm{cc}$ from Equation 44.

$\rho_{a c 254}=2.54-\mathrm{cm}$ aluminum standard "corrected" density of 1.00 $\mathrm{g} / \mathrm{cc}$ when assuming a $6.61-\mathrm{cm}$ diameter in its calculation

$\rho_{\text {as } 254}=2.54-\mathrm{cm}$ aluminum standard of the magnetic tape data, $\mathrm{g} / \mathrm{cc}$, from Equation 43

$\rho_{a c \Delta, 01}=6.61-\mathrm{cm}$ aluminum standard "corrected" density of 2.60 $\mathrm{g} / \mathrm{cc}$

$\rho_{a s, 61}=6.61-\mathrm{cm}$ aluminum standard of the magnetic tape data, $\mathrm{g} / \mathrm{cc}$, from Equation 42.

Therefore it is possible to solve for $\rho_{b c}$ :

$$
\rho_{b c}=\left[\frac{\left(\rho_{b s}-\rho_{a s 2.54}\right)\left(\rho_{a c 6.61}-\rho_{a c 2.54}\right)}{\rho_{a s 6.61}-\rho_{a s 2.54}}\right]+\rho_{a c 2.54}
$$

The Magnetic Tape Data in the form of Equation 42, 43, and 44 may be substituted into this formula as follows:

$\rho_{b c}=\left\{\frac{\left[\frac{1 \mathrm{n}\left(I_{o} / I_{s}\right)}{\mu_{x} 6.61 \mathrm{~cm}}\right]-\left[\frac{1 \mathrm{n}\left(I_{o} / I_{a 2.54}\right.}{\mu_{x} 6.61 \mathrm{~cm}}\right]\left(\rho_{a c 6.61}-\rho_{a c 2.54}\right)}{\frac{\ln \left(I_{o} / I_{a 6.61}\right)}{\mu_{x} 6.61 \mathrm{~cm}}-\frac{\ln \left(I_{o} / I_{a 2.54}\right)}{\mu_{x} 6.61 \mathrm{~cm}}}\right\}$

$$
+\rho_{a c 2.54}
$$

This equation then reduces down to the following:

$$
\rho_{b c}=\left[\frac{\left(\ln I_{a 2.54}-\ln I_{s}\right)\left(\rho_{a c 6.61^{-\rho_{a c 2.54}}}\right)}{\ln I_{a 2.54^{-1}} \operatorname{n}_{a 6.61}}\right]+\rho_{a c 2.54}
$$

or

$\rho_{b c}=\left[\frac{\left(\ln I_{s}-\ln I_{a 2.54}\right)\left(\rho_{a c 6.61}-\rho_{a c 2.54}\right)}{\ln I_{a 6.61}-\ln I_{a 2.54}}\right]+\rho_{a c 2.54}$

In reality the $I_{O}$ drops out of the equation, therfore for the magnetic tape records we do not need to measure $I_{O}$, and we can place the $I$ data from the magnetic tape into Equation 51 and determine the "corrected" wet-bulk density. Withh the "corrected" bulk density any other sample geometric adjustments can be made before the true wetbulk density can be calculated by Equation 27. Legs 21-28 inserted the "corrected" wet-bulk density at this point into the Whitmarsh iteration.

In reality the $I_{O}$ is used to monitor the $\mathrm{MeV}$ of the equipment and is used in determining the mass attenuation coefficients for the GRAPE Special 2-Minute Data.

"The value of $1.00 \mathrm{~g} / \mathrm{cc}$ was changed to $1.03 \mathrm{~g} / \mathrm{cc}$ for Leg 33 data, as a result of the sample thickness problem discussed in the section titled "DSDP GRAPE Application in Static Mode." 
APPENDIX F

\section{HISTORY OF GRAPE EQUIPMENT AND PROGRAM CHANGES}

For a history of equipment and program changes with the GRAPE as used by DSDP, see Table 19.

TABLE 19

History of GRAPE Equipment, Procedure, and Shore-Based Computer Program Changes

Legs

1,2 Seven (7) $\mathrm{cm}$ long aluminum $(6.61 \mathrm{~cm}$ diameter) standard in liner, and $13 \mathrm{~cm}$ long sea water (6.61 diameter) standard in liner. Data reduction techniques used are not published.

3 Data reduced by Equations 29, 30, and 31 for Legs 3 through 11.

12 Data reduced by Whitmarsh (1971) iteration, also described in Boyce (1973) (typographical errors described in the introduction of the present paper).

15 First geometric adjustments made (Boyce, 1973) and Equations 33 through 37 in this paper, for rocks with smaller diameter than the standards, not necessarily done on subsequent legs.

16 Sea water standard replaced by distilled water.

18 New routine standards: $25 \mathrm{~cm}$ long $(6.61 \mathrm{~cm}$ diameter) aluminum and $25 \mathrm{~cm}$ long (2.54 cm diameter) aluminum. Optional to run water standard with new aluminum standards in order to empirically calibrate the smaller diameter aluminum standard. New punch core standards $25 \mathrm{~cm}$ long
TABLE 19 - Continued

$(5.71 \mathrm{~cm}$ diameter) aluminum and $(5.71 \mathrm{~cm}$ diameter $)$ distilled water standards.

19 Pre- and postsite multidiameter aluminum "telescope" standard (optional). Experimental magnetic tape which was unusable.

21 First usable experimental digital system and magnetic tape. The Evans (1965) Analog GRAPE record is still run for shipboard use and backup for bad magnetic tape data. First mandatory routine use of pre- and postsite standards, see Table 17 for codes and what standards were run.

22 First set of magnetic tape data which was published. Preprocessing of magnetic tape as described in Appendix E, to obtain "corrected" density before using the Whitmarsh iteration.

26 New magnetic tape codes used which are in Table 16.

28 Magnetic tape not operational for this leg only.

29 Used new computer program for data reduction. Results are identical with the Whitmarsh program, but the new program is more efficient and less expensive to run on computer. Basic Equations are 15 through 28 and with the proper diameter adjustments of Equations 33 through 37, and the details of preprocessing of the magnetic tape data discussed in Appendix D.

33 First use of Russill Calipers Model I, which are described with techniques in Appendix A.

38 Russill Calipers Model II, which are described with techniques in Appendix A. 